IZA DP No. 7537

The Importance of Early Conscientiousness for Socio-Economic Outcomes: Evidence from the British Cohort Study

Tyas Prevoo

Bas ter Weel

July 2013 


\title{
The Importance of Early Conscientiousness for Socio-Economic Outcomes: Evidence from the British Cohort Study
}

\author{
Tyas Prevoo \\ Maastricht University \\ Bas ter Weel \\ CPB Netherlands Bureau for Economic Policy Analysis, \\ Maastricht University and IZA
}

\author{
Discussion Paper No. 7537 \\ July 2013
}

IZA

P.O. Box 7240

53072 Bonn

Germany

Phone: +49-228-3894-0

Fax: +49-228-3894-180

E-mail: iza@iza.org

Any opinions expressed here are those of the author(s) and not those of IZA. Research published in this series may include views on policy, but the institute itself takes no institutional policy positions. The IZA research network is committed to the IZA Guiding Principles of Research Integrity.

The Institute for the Study of Labor (IZA) in Bonn is a local and virtual international research center and a place of communication between science, politics and business. IZA is an independent nonprofit organization supported by Deutsche Post Foundation. The center is associated with the University of Bonn and offers a stimulating research environment through its international network, workshops and conferences, data service, project support, research visits and doctoral program. IZA engages in (i) original and internationally competitive research in all fields of labor economics, (ii) development of policy concepts, and (iii) dissemination of research results and concepts to the interested public.

IZA Discussion Papers often represent preliminary work and are circulated to encourage discussion. Citation of such a paper should account for its provisional character. A revised version may be available directly from the author. 


\section{ABSTRACT \\ The Importance of Early Conscientiousness for Socio-Economic Outcomes: Evidence from the British Cohort Study*}

This research estimates models of the importance of conscientiousness for socio-economic outcomes. We use measures of conscientiousness at age 16 to explain adult wages and other outcomes, such as crime, health and savings behaviour. We use several waves from the 1970 British Cohort Study. Our estimates suggest a significant and sizeable correlation between early conscientiousness and adult outcomes. Measurement error is corrected for by applying IV-techniques, errors-in-variables estimators and structural equation modelling. Investigation of the lower-order structure of conscientiousness suggests that facets related to reliability, decisiveness and impulse control are most strongly correlated with outcomes. We also investigate changes in early conscientiousness and find that persons who experience declines in the personality distribution between the ages 10 and 16 seem to be worse off in terms of a variety of socio-economic outcomes.

JEL Classification: J24

Keywords: conscientiousness, personality traits, socio-economic outcomes, preferences

Corresponding author:

Bas ter Weel

CPB Netherlands Bureau for Economic Policy Analysis

P.O. Box 80510

2508 GM The Hague

The Netherlands

E-mail: b.ter.weel@cpb.nl

\footnotetext{
"We would like to thank Lex Borghans, Thomas Dohmen, Roel van Elk, Bart Golsteyn, Jim Heckman, Suzanne Kok, Erzo Luttmer, Ellen Meara, Erik Plug and Dinand Webbink for very useful comments on an earlier version of this paper. Seminar participants at the CPB, the 2012 EEA Meetings in Malaga, the 2012 ESPE conference in Bern, the 2012 CEPR/IZA ESSLE conference in Buch am Ammersee, Maastricht University and the University of Groningen provided useful insights.
} 


\section{Introduction}

For many socio-economic outcomes personality is as predictive as cognition. Economists have recently been drawing attention to differences in personality as a key consideration to explaining individual outcomes (e.g., Borghans et al., 2008a and Almlund et al., 2011 for reviews of this literature). Evidence from other academic disciplines, such as the neurosciences, behavioural genetics and psychology, suggests that differences in personality are important in explaining a variety of socio-economic outcomes. ${ }^{1}$ A growing body of evidence from personality psychology suggests that especially personality measures related to conscientiousness predict a range of socio-economic outcomes. ${ }^{2}$ Conscientiousness is broadly defined and referred to as the propensity to follow socially prescribed norms and rules to be goal-directed, able to delay gratification and to control impulses (e.g., McCrae and Costa, 1994, John and Srivastava, 1999). ${ }^{3}$

In this paper we investigate the role of early conscientiousness in explaining a range of socioeconomic outcomes. We do so in an empirical fashion and apply several strategies to move towards predictions. In particular we deal with measurement error in traits by using instrumental variables techniques (2SLS), errors-in-variables (EIV) regressions and structural equation modelling (SEM). Furthermore, it is not clear which facets of conscientiousness are important for what outcomes. The inputs that have been used to construct measures of conscientiousness seem to come close to what economists have defined as measures of time discounting, risk aversion and social preferences. At this point, empirical knowledge is too limited to judge how conscientiousness relates to the concepts and parameters economists typically model to predict outcomes, but by investigating the lower-order structure of conscientiousness we present a set of estimates constructive to understanding differences in socio-economic outcomes and useful to bridging gaps between economists and psychologists.

We empirically explore the link between early personality indicators and a range of socioeconomic outcomes at age 34. The outcomes are adult wages, saving behaviour, indicators of

\footnotetext{
${ }^{1}$ See e.g., Cunha et al. (2006), Knudsen et al. (2006), Heckman (2007), Borghans et al. (2008a), Roberts (2009), Dohmen et al. (2010), Almlund et al. (2011), Lebel and Beaulieu (2011) and Moffitt et al. (2011).

${ }^{2}$ See Roberts et al. (2004; 2008) and Jackson et al. (2009) for meta-analyses with conscientiousness as a predictor for outcomes. They summarise and review the literature from personality psychology. Almlund et al. (2011) present an overview of evidence from other academic fields on the importance of conscientiousness.

${ }^{3}$ Moffitt et al. (2011) present evidence that conscientiousness, which they define as part of the umbrella of selfcontrol, predicts a range of socio-economic outcomes, such as physical health, substance dependence, personal finances and criminal offending outcomes. The pattern they obtain is a gradient in which children with less selfcontrol have worse adult outcomes. They also show that children who move up the self-control rank (from childhood to young adulthood) obtain better outcomes as adults.
} 
health (body mass index (BMI), alcoholism, smoking, drug use), involvement in criminal activities, and a number of indicators for life satisfaction. The database of the working population is constructed from several waves of the British Cohort Study (BCS). The data include personality items at age 16. We use these items to build a personality inventory consistent with the Big Five personality inventory. ${ }^{4}$ In addition, we decompose conscientiousness to investigate the facets important in explaining different outcomes. Finally, changes in conscientiousness between ages 10 and 16 are used to shed light on the importance of its development during childhood.

We find that a one standard deviation increase in conscientiousness increases hourly wages by 4.1 per cent. For other outcomes conscientiousness seems to be important too. Higher levels of conscientiousness are associated with less unhealthy behaviour and crime, and with higher savings and life satisfaction. Adding controls for the child's home environment, educational outcomes, other measures of personality (Rutter scores, self-esteem and locus of control) and social behaviour in school at age 16 does not alter our conclusions. Our estimates of conscientiousness remain similar in terms of significance and size. The same holds when accounting for the fact that people with different personality traits sort into different occupations.

We address measurement error in three ways as applied by Heckman et al. (2006) and Cunha et al. (2010). First, we apply instrumental variables techniques (2SLS) in which we instrument the age 16 personality traits with the same traits, as observed at age 10. This way we deal with possible correlation between the error term and traits. Second, we use structural equation modelling (SEM), which is based on maximum likelihood. The main advantage of SEM is that it takes into account measurement error at the level of the individual items we use to construct our personality traits. Finally, we apply errors-in-variables (EIV) regressions, which is a latent variable technique dealing with the fact that we possibly measure personality with error. Our estimates remain similar both in terms of magnitude and significance.

Next, we explore the lower-order structure of conscientiousness following the decomposition made by personality psychologists (e.g., Roberts et al., 2004 and Jackson et al., 2009). The main facets of conscientiousness are impulse control, reliability, decisiveness and orderliness.

\footnotetext{
${ }^{4}$ The Big Five personality inventory is the most commonly used inventory for measuring personality traits. It includes five measures: openness, conscientiousness, extraversion, agreeableness and neuroticism (or emotional stability). See Borghans et al. (2008a) for an elaborate overview of the history, use across disciplines and potential problems of this way of characterising personality.
} 
Our estimates suggest that higher levels of early impulse control, reliability, and decisiveness are facets that are correlated with socio-economic outcomes. In general, the facet of orderliness has the least relevance for the socio-economic outcomes considered. Higher levels of decisiveness are correlated with higher wages and savings, and less unhealthy behaviours and crime. The same is true for facets related to impulse control and reliability.

Finally, we examine changes in conscientiousness during childhood. Much policy effort has gone into trying to improve cognitive ability and a child's home environment. Our findings suggest that there is a gradient of conscientiousness that is worthwhile investigating. Controlling for age-10 conscientiousness, persons who face declines in the conscientiousness distribution between the ages of 10 and 16 end up with significantly less favourable scores on our socio-economic outcomes. Those experiencing a decline in conscientiousness during childhood are significantly more likely to be alcohol dependent, to smoke, use cannabis or get arrested as adults, while also reporting significantly lower life satisfaction and a less healthy body mass index.

The analysis presented in this paper contributes to a recent literature in economics that has focused on the distinction between cognitive and non-cognitive skills. It has been triggered by the outcomes of intervention programmes, in which the most prominent outcome has been better behaviour, not better cognitive skills (e.g., Schweinhart et al., 2005, Heckman et al., 2007). Cunha and Heckman (2007, 2008) and Cunha et al. (2010) estimate models of skill formation with the notion of complementarity between different types of skills. The results most relevant for our work emphasise the role of personality traits that seem to be important for later outcomes. We contribute to this literature by presenting estimates that show the importance of (specific facets of) conscientiousness for socio-economic outcomes.

A closely related body of work applies these models more directly to labour-market outcomes to show the relevance of personality traits. Heckman et al. (2006) and Cobb-Clark and Schurer (2013) show the relevance of and changes in personality traits (locus of control and self-esteem) over the lifecycle. Mueller and Plug (2006) estimate the effect of personality on earnings. They find that some personality traits are penalised whereas others have positive returns. Borghans et al. (2008c), Krueger and Schkade (2008), Antecol and Cobb-Clark (2010) and Cobb-Clark and Tan (2011) show the importance of occupational sorting when measuring the returns to different traits. This has recently also been picked up in personality psychology by Roberts (2009) who emphasises the importance of different environments and 
states in which people perform. Finally, early work by Filer (1983), as well as more recent work by Borghans et al. (2006) and Grove et al. (2011), suggests that personality is important in explaining labour-market outcomes and gender wage differentials. We also take into account the importance of sorting and add to these approaches a longitudinal approach and a distinction between types of traits.

Thirdly, economists and psychologists have been trying to link economic preference parameters to personality traits to predict outcomes. ${ }^{5}$ Borghans et al. (2008a) and Almlund et al. (2011) summarise these attempts and suggest models for understanding and building productive linkages. Becker et al. (2012) empirically explore three datasets to link personality traits to economic preference parameters and find complementarity between the two. Borghans et al. (2008b) find that performance motivation, fear of failure, internal locus of control, curiosity, low discount rates, and risk aversion are positively associated with more correct answers on a cognition test. Our results are also consistent with experimental evidence from Sutter et al. (2012), who find that students with higher levels of impulse control fare better in school and are more likely to obtain good labour-market outcomes. We use a longitudinal approach to find the predictive power of conscientiousness and relate the lower-order structure to evidence on economic preference parameters.

We proceed as follows. Section 2 documents the construction of the database from the BCS and presents descriptive statistics. Section 3 presents a set of basic estimates showing correlations between early personality traits and adult outcomes. Section 4 deals with the effects of measurement error. Section 5 explores the anatomy of conscientiousness by considering the lower-order structure of personality traits. Section 6 discusses the importance of changes in personality traits during childhood. Section 7 concludes.

\section{Data}

We analyse socio-economic outcomes of employed persons as measured in the 2004 wave of the British Cohort Study (BCS). The BCS is available from the Centre for Longitudinal

\footnotetext{
${ }^{5}$ Unfortunately our database does not contain measures of preference parameters. Nevertheless, impulse control is related to risk aversion, reliability is related to social preferences, and decisiveness is related to time preference (e.g., Daly et al., 2009). These three facets are the strongest predictors for the set of outcomes considered. More precisely, higher scores on impulse control are correlated with higher wages and savings and lower rates of unhealthy behaviour. This seems consistent with the evidence in economics about risk aversion (e.g., Dohmen et al., 2010). Similarly, higher levels of decisiveness are correlated with higher wages, less crime and better health outcomes, which is consistent with the evidence on time discounting (e.g., Frederick et al., 2002). Finally, higher levels of reliability are correlated with higher scores on life satisfaction, health outcomes and wages. The facet of reliability is related to social preferences. Reliable persons are more likely to be trustworthy and are more altruistic (e.g., Fehr, 2009).
} 
Studies (Institute of Education, University of London). The database contains data on births and families of all babies born in Great Britain in one particular week in April, 1970. These children were then followed throughout their lives, and data were collected roughly every 4 to 5 years. The last available wave is from 2008 .

The main strength of the BCS is that it follows a complete cohort for a substantial period of time, which allows for an analysis of adult socio-economic outcomes. The BCS contains a wide range of items measuring cognitive and personality development. Data on children and their families were collected when the respondents were aged $0,5,10$, and 16. The adult waves at ages $26,30,34$, and 38 provide a set of outcome variables. In terms of adult outcomes we use the 2004 wave. There are two reasons. First, at the age of 34, all persons have left education and have been working for a while. This should yield reliable information about labour-market outcomes and other social outcomes. Second, we prefer to use the 2004 wave over the 2008 wave, because of the larger sample.

Of the initial 17,196 babies born in 1970, 9,665 respondents remain in 2004. Of this group, 8,013 are employed, of which 6,106 report gross hourly wages. After further selecting individuals with valid information on childhood ability and personality, we retain a working sample of 2,934 respondents used for the analyses in this research. The selection on age-16 personality leads to a substantial loss of respondents, as a teacher's strike in 1986 resulted in many subjects not receiving their questionnaires (SSRU, 1986). Table A1 in the Appendix lists all variables and the way in which they are constructed or defined. Issues of attrition and selection based on being employed and providing wage information are discussed in Section 2.4 and illustrated in Table A2.

\subsection{Personality Measures}

Personality psychologists have developed measurement systems for personality traits, which economists have begun to use. Most prominent is the Big Five personality inventory, which contains five personality traits (OCEAN): openness, conscientiousness, extraversion, agreeableness and neuroticism (emotional stability).

The Big Five taxonomy of personality allows us to capture the relative importance of different dimensions of an individual's personality (e.g., McCrae and John, 1992 and Goldberg, 1993). The schedule below presents the descriptions of the traits as agreed upon by the American Psychology Association. The final column presents facets of these five 
personality traits measured in Child surveys. The BCS offers items on personality and behaviour from which we are able to construct measures capturing a child's conscientiousness, extraversion, agreeableness and emotional stability. It is not possible to capture openness with the available items. ${ }^{6}$

\begin{tabular}{|c|c|c|}
\hline Big Five factor & $\begin{array}{l}\text { American Psychology Association } \\
\text { Dictionary description }\end{array}$ & Childhood traits \\
\hline Openness & $\begin{array}{l}\text { "the tendency to be open to new } \\
\text { aesthetic, cultural, or intellectual } \\
\text { experiences" }\end{array}$ & $\begin{array}{l}\text { Sensory sensitivity, pleasure in low } \\
\text { intensity activities, curiosity }\end{array}$ \\
\hline Conscientiousness & $\begin{array}{l}\text { "the tendency to be organised, } \\
\text { responsible, and hardworking" }\end{array}$ & $\begin{array}{l}\text { Attention, distractibility, effortful, } \\
\text { self-control, impulse control, } \\
\text { persistence, activity }\end{array}$ \\
\hline Extraversion & $\begin{array}{l}\text { "an orientation of one's interests and } \\
\text { energies toward the outer world of } \\
\text { people and things rather than the inner } \\
\text { world of subjective experience; } \\
\text { characterised by positive affect and } \\
\text { sociability" }\end{array}$ & $\begin{array}{l}\text { Social dominance, social vitality, } \\
\text { sensation seeking, shyness, activity, } \\
\text { positive emotionality, } \\
\text { sociability/affiliation }\end{array}$ \\
\hline Agreeableness & $\begin{array}{l}\text { "the tendency to act in a cooperative, } \\
\text { unselfish manner" }\end{array}$ & $\begin{array}{l}\text { Irritability, aggressiveness, } \\
\text { wilfulness }\end{array}$ \\
\hline $\begin{array}{l}\text { Neuroticism/ } \\
\text { Emotional Stability }\end{array}$ & $\begin{array}{l}\text { Neuroticism is "a chronic level of } \\
\text { emotional instability and proneness to } \\
\text { psychological distress." } \\
\text { Emotional stability is "predictability } \\
\text { and consistency in emotional reactions, } \\
\text { with absence of rapid mood changes." }\end{array}$ & $\begin{array}{l}\text { Fearfulness, behavioural inhibition, } \\
\text { shyness, irritability, frustration, } \\
\text { sadness }\end{array}$ \\
\hline
\end{tabular}

Mothers are asked to rate the behaviour of their child at ages 10 and 16 . We group 22 items into four clusters, representing conscientiousness, extraversion, agreeableness, and emotional stability. The clustering is consistent with the clustering obtained by personality psychologists (e.g., Goldberg, 1993), and confirmed by both cluster analysis and principal component analysis on the set of 22 items. $^{7}$ The first four components of the principal component analysis return eigenvalues larger than one, and after orthogonal rotation, the items load highly on their respective factors (and not on the other factors). The results of

\footnotetext{
${ }^{6}$ Personality traits are distinguished from intelligence. Most measures of personality are only weakly correlated with measures of cognitive ability (e.g., Webb 1915, McCrae and Costa 1994). There are, however, a small number of exceptions. Most notably, cognitive ability is moderately associated with Openness. The reported correlations are of the order of .3 or lower (e.g., Borghans et al., 2008a for a review). We compensate for the lack of a measure of openness by including cognitive test scores.

${ }^{7}$ Similar items have been used to diagnose mental health conditions (e.g. Currie and Stabile, 2006). However, the items in the BCS are consistent with those identified by the American Psychology Association Dictionary as capturing Big Five personality traits.
} 
these analyses are described in the Appendix (Section A1). Note that factorization of the items and their loadings using factor analysis are consistent with those obtained from cluster analysis and principal component analysis.

Each trait is measured by extracting the first principal component from the set of items belonging to that trait. To increase the number of observations, we impute missing values for individuals who miss 1 or 2 of the 22 items used for constructing our personality measures. We apply multiple imputations through chained equations using the remaining 21 items as predictors for the item of interest. Table 1 shows the grouping of the 22 mother-rated personality items into the four personality domains, along with the reliability of the resulting constructs, both for the set of items without and with imputed missing observations. Conscientiousness, agreeableness, and emotional stability show strong reliability, with Cronbach's alphas of .8 (indicating .36 error variance in the scores of their items). Extraversion has a Cronbach's alpha of .6. The principal component for conscientiousness captures 65 per cent of the variance in its items. For extraversion, this number is 37 per cent, and the constructs for agreeableness and emotional stability explain 45 and 56 per cent of the variance in their items, respectively. ${ }^{8}$

\subsection{Outcome Measures}

We measure adult outcomes at age 34 . The gross hourly wage is one outcome measure. It is defined as gross pay per week divided by usual hours worked per week. Respondents report their gross pay alongside the period of pay, which may be one week, two weeks, four weeks, a calendar month, or a year. Observations in the lowest and highest percentile are deleted, which means excluding those reporting earnings below 32.5 pounds or above 3,073 pounds per week. Further, we exclude those reporting to work more than 80 or fewer than 5 hours per week, as well as those reporting to work full-time, but reporting fewer than 30 weekly working hours. ${ }^{9}$

Next to wages, a number of other socio-economic outcomes are considered. A dummy for savings behaviour indicates whether or not respondents save any amount of their monthly income (Save). We observe health by looking at the Body Mass Index (BMI), the CAGE

\footnotetext{
${ }^{8}$ Personality items are constructed on the basis of the item loadings obtained from using the full sample (including imputed items). The loadings are almost identical if we restrict the sample to the working sample of 2,934 respondents used for all analyses. The same is true when we exclude the imputed items.

${ }^{9}$ We do not include hours worked overtime in our calculations. Removal of outliers, by deleting observations with gross hourly wages below 2 or above 50 pounds, yields similar results; using net wages and using age 30 or age 38 wages does so too. These results are available upon request.
} 
measure for alcoholism (Alcoholic), and whether or not the respondent is a smoker (Smoke). A value of zero on our smoking dummy includes individuals who have never smoked before, but also ex-smokers. A value of one includes occasional smokers, as well as respondents smoking more than 20 cigarettes a day. The CAGE index is an assessment for alcohol dependence and alcohol abuse using self-reported answers to four yes-or-no questions. We construct a dummy for alcoholism using a cut-off point of 2 ( 0 if the score is below $2 ; 1$ otherwise) on the four items of the CAGE questionnaire. ${ }^{10}$

Criminal behaviour is constructed by applying two dummy variables, indicating whether or not the individual uses cannabis on a regular basis (Cannabis) $)^{11}$ and whether or not the respondent has been arrested between ages 16 and 34 (Arrested). For cannabis use, a value of zero indicates the respondent either has never tried cannabis, or has used cannabis in the past, but never uses it nowadays. Values of one include respondents who use cannabis regularly, be it only on special occasions or on most days. The dummy for arrests equals zero if the respondent indicated never to have been arrested before and one if (s)he had been arrested at least once.

Finally, we measure life satisfaction with three different variables. On a scale from 0 to 10 , respondents are asked to indicate how satisfied or dissatisfied they are with the way life has turned out so far (Satisfaction). In addition to this life satisfaction scale, we use two dummy indicators that indicate whether respondents feel they get what they want out of life (Life Get), and whether they feel they can usually run their life more or less as they want to (Life Run). In both cases, a value of one indicates a positive view to life, whereas a value of zero indicates, respectively, that respondents feel they never really seem to get out of life what they want and that they usually find life's problems just too much to handle.

\subsection{Other Measures}

Besides the personality measures and outcome measures discussed above, we also extract information about cognitive ability and various other measures which we use as controls in our models. We consider a child's cognitive ability. We construct a measure using test scores at age 10 because cognitive ability seems to be set at that age in the sense that it is rank-order stable (e.g., Lebel and Beaulieu, 2011). Cognitive ability is measured by extracting the first

\footnotetext{
${ }^{10}$ The CAGE questionnaire has been validated as a screening tool in general population samples, using the same cut-off point of 2 (e.g., King, 1986, Buchsbaum et al., 1991).

${ }^{11}$ Cannabis use is both a measure of health and of criminal behaviour, since it is illegal in the United Kingdom.
} 
principal component from a set of eight standardised test scores, all measured at the age of 10. The test scores include the four British Ability Scales (word definitions, recall of digits, similarities, matrices), as well as the Shortened Edinburgh Reading Test, the CHES Pictorial Language Comprehension and Friendly Maths tests, and a spelling test. Cronbach's alpha on the set of test scores is .89 and the explained variance of the resulting principal component is 58 per cent.

School performance, the home environment a child grew up in, social skills as a child, and final education and occupation are also measured. These other measures are used alongside the Big Five personality measures to estimate the effects of personality on outcomes, and are introduced and discussed in Section 3. Table A1 provides the definitions and construction of the various variables. Table A2 presents descriptive statistics for these variables, both for the restricted working sample of 2,934 employed respondents with wage information and the unrestricted sample containing all respondents.

\subsection{Selection}

When we restrict our sample to employed respondents with valid wage information, the sample shows significant differences in terms of personality and socio-economic outcomes compared to the full population of respondents with valid information on these measures (the unrestricted sample). As Table A2 reveals, the working sample scores about a tenth of a standard deviation higher on all personality traits. The unrestricted sample shows a higher share of smokers, cannabis users, and arrests, and is on average less satisfied with life than when we restrict the sample to the working sample.

The same holds for the different sets of control variables. Parents of the average respondent in the working sample are more highly educated and have higher social class. Subjects themselves are also more highly educated and have higher social class, while also displaying less behavioural problems and higher self-esteem and internal locus of control as a child. Selection on being employed and reporting wages significantly affects the sample statistics, and might also influence the estimated relationship between personality and outcomes. While all analyses in this paper are restricted to the working sample for consistency in the estimation population, the results remain both qualitatively and quantitatively similar when relaxing this selection for the other socio-economic outcomes. ${ }^{12}$

\footnotetext{
${ }^{12}$ These results are available on request.
} 


\subsection{Descriptive Statistics}

Table 2 shows the correlations between the four personality traits as well as their correlations with our outcome measures. This yields a first indication of the relationship between childhood personality and adult outcomes. Conscientiousness consistently shows the strongest correlations. A more detailed picture of the correlation between conscientiousness and outcomes is presented in Figure 1. It shows mean outcomes by deciles of conscientiousness. The upper deciles are put together because we cannot discriminate in terms of conscientiousness. There is a clear gradient in conscientiousness for most outcomes, where those lower in the distribution of conscientiousness obtain less favourable outcomes than those higher in the distribution. The bottom ten per cent report average gross hourly wages below 11 pounds, whereas the top forty per cent earn over 14 pounds per hour. In terms of smoking behaviour, the bottom ten per cent is twice as likely to smoke compared to the top forty per cent (40 vs. 20 per cent). As can be seen from Figure 1, similar patterns are obtained for other outcomes.

Since we want to explore the relationship between childhood conscientiousness and a range of adult socio-economic outcomes, we need to account for possible confounding relationships. Cognitive ability, the home environment, sociability and education are all domains that relate to adult wages and other socio-economic outcomes as well as to childhood personality. They may therefore also influence estimates of the relationship between personality traits and socio-economic outcomes. Table A3 in the Appendix compares respondents who score below average on wages and the four personality traits with those who score above average on each of these measures. Below and above average scorers are compared in terms of averages on variables relating to the above mentioned domains. The obtained patterns suggest that there are sizeable associations between these domains and both wages and personality.

Those ending up earning above average hourly wages by age 34 scored significantly higher on all personality measures, both at age 10 and age 16 . Consistent with the notion that cognitive ability and education have significant effects on labour-market outcomes, they also scored significantly higher on ability tests and went on to complete more years of schooling. Additionally, above average earners had significantly better home environments when growing up and scored significantly higher on most measures of sociability. Those with above average conscientiousness or agreeableness had better home environments when 
growing up. To a lesser extent, the same holds for extraversion and emotional stability. Above average personality traits are also associated with significantly higher sociability measures; this applies to all four traits, specifically to agreeableness.

When it comes to the association between personality traits and cognitive ability and educational achievements, the differences between the below- and above-average groups are significant for conscientiousness and agreeableness, and most pronounced for conscientiousness. Those with above average conscientiousness score .4 of a standard deviation higher on our cognitive ability measure. Above average conscientiousness is also associated with completing about 1.2 years more schooling.

Since both outcomes and personality traits are associated with childhood circumstances, sociability and final educational achievement, it seems important to control for these domains when estimating the relationship between personality traits and outcomes. Given the sizeable and significant association between personality traits and ability measures, as observed in Table A3, it is also important to account for cognitive ability in our models.

\section{Conscientiousness and Outcomes}

Our first task is to show that there is a sizeable correlation between measured conscientiousness at age 16 and adult outcomes. This section presents estimates with different sets of controls.

\subsection{Basic Estimates}

Table 3 presents estimates of models in which outcomes are explained by measured personality traits at age 16 . Control variables for cognitive ability at age 10, region of birth and dummies for gender and fulltime employment are added to these models. Investigation of the four rows in Table 3 reveals that there is a statistically significant correlation between all adult outcomes and the measure of conscientiousness. Agreeableness is also correlated with most outcomes, yet to a lesser extent when compared to the correlations for conscientiousness. The correlations for extraversion are mixed in nature, with higher childhood extraversion being associated with higher adult satisfaction with life, but also with less savings, higher rates of tobacco and cannabis use, and higher rates of arrest. The measure of emotional stability is only significantly correlated with savings and crime. The size of the coefficients varies. In general, the size of the coefficient on conscientiousness is the largest. 
Since our personality measures are standardised to have mean zero and a standard deviation of one within each regression sample, the coefficients can be interpreted as a ceteris paribus change in the outcome measure for a one standard deviation increase in the measured personality traits. Using this way of interpreting the estimates, individuals who have a one standard deviation above average conscientiousness at the age of 16, earn on average 4.1 per cent higher gross hourly wages $\left(e^{-.0400}-1\right)$ by the age of 34 . Their BMI at that age is .22 points lower, and (on a scale from 0 to 10 ) they rate their life satisfaction .11 points higher. On average, they are also 3.2 percentage points more likely to save, 3.2 percentage points less likely to be alcoholic, 4.2 percentage points less likely to smoke, and 2 percentage points less likely to use cannabis on a regular basis. A one standard deviation increase in conscientiousness is further associated with a 1 percentage point lower likelihood of ever having been arrested, and with improved feelings of getting out of life what one wants and feeling one can run one's life as desired (2.9 and .7 percentage points higher, respectively).

The same analysis has been performed for men and women separately. Using data from the Wisconsin Longitudinal Study, Mueller and Plug (2006) find that the coefficients on the different traits differ across gender. This merits further analysis because they find that especially female outcomes are sensitive to differences in conscientiousness. However, we do not find statistically significant differences between the sexes when we repeat the analysis presented in Table 3 for men and women separately. ${ }^{13}$ The effect sizes for males are somewhat higher and for females they are somewhat lower. The estimated effects on wages (comparable to Table 3, column (1)) are .0544 for men and .0244 for women. The estimated effects remain statistically significant. The estimation results split by gender are available upon request.

\subsection{Extensions}

The fact that conscientiousness at age 16 is correlated with later-life outcomes needs further analysis. We extend the analysis into four directions. First, we investigate the role of parents and the home environment. A sound home environment and parental inputs are key factors for child development (e.g., Herrnstein and Murray, 1994 and Shonkoff and Phillips, 2000). Second, we examine the role of education. Abilities and traits are to a large extent created and education may help to build these (e.g., Cunha et al., 2010). Third, we add measures of

\footnotetext{
${ }^{13}$ The only exception is regular use of cannabis. The effects of conscientiousness on cannabis use are only significant for men. When adding interaction terms of personality traits with the male dummy, the differences in coefficients for men and women are only significant for cannabis use.
} 
sociability, self-esteem and locus of control. These covariates help shape a more balanced personality and are positively correlated with labour-market success (e.g., Persico et al., 2004, Heckman et al., 2006 and Borghans et al., 2008c). Finally, we conduct analyses in which we control for the average level of personality traits within one's occupation. The reason for doing so is that absolute levels of personality traits could be misleading and that relative measures determine success (e.g., Gronau, 1974 and Borghans et al., 2008c).

Table 4 and Table 5 present the results. Whereas Table 4 only reports the coefficient on conscientiousness, Table A4 in the Appendix displays the estimates for the other three measures of personality in the same way as documented in Table 4.

\subsubsection{Home Environment}

If it is the home environment that is the key factor influencing adult wages, personality traits should have no effect on outcomes if we control for parental investments. We add a number of controls for the child's home environment to the basic model: dummies for the absence of the father at birth and for having a teenage mother; years of education of the parents; social class of the parents measured by whether or not parents had a skilled or professional occupation when the child was born; parenting styles and parent-child relationships; parents holding of a liberal worldview; parental beliefs in giving a child some freedom and teaching the child discipline at age 5; the child's view on family ties at age 10, and on parental skills at age $16 .^{14}$

The variables are documented and defined in Table A1 and descriptive statistics are shown in Tables A2 and A3 in the Appendix. The descriptive information presented in Table A3 suggests that above average earners grew up in more beneficial home environments. Their parents completed more years of schooling and had a higher social class. At age 5, their parents had a more liberal world view and believed less in strict authoritarian childrearing. At age 10, they experienced stronger family ties than below average earners did at that age.

The first row of Table 4 shows that controlling for the home environment does not substantially affect the correlation between the measure of early conscientiousness and adult

\footnotetext{
${ }^{14}$ Adding more covariates to the regression models reduces the number of observations. However, the pattern of results remains similar. Parental social class, childrearing style, and good parent-child relationships do seem to matter most in terms of explaining outcomes. Additional measures associated with the home environment are number of younger and older siblings (at ages 5, 10, and 16), being read to as a 5-year old, being in a single parent family and living with both natural parents (at ages $0,5,10$, and 16), and having experienced separation, divorce, and/or death of parent(s) between birth and age 16. When adding these to our models, they do not significantly affect outcomes, nor do they have an impact on the estimated effects of personality.
} 
outcomes. The coefficients are comparable to the ones in Table 3, and remain significant, except for the coefficients on BMI, alcohol dependence and crime (being arrested). While similar in magnitude, these coefficients are no longer statistically significant.

\subsubsection{Education}

The positive relationship between educational achievement and wages is well-known, and is also apparent from Table A3. If personality is predictive of outcomes because it affects final educational achievement, controlling for education would result in insignificant, or significantly lower, estimated effects for conscientiousness. To control for educational attainment, we use completed years of schooling. ${ }^{15} \mathrm{We}$ also control for social class by adding a dummy that equals one if the respondent's job is of a skilled or professional nature. The second row of Table 4 shows that the results of these analyses do not alter the picture, with the exception of crime. In general, measured conscientiousness is correlated with measures of education and social class, but the estimated correlations between conscientiousness and outcomes are not significantly affected.

The estimated effects of education and social class on wages are relatively large. In a causal interpretation of the estimates, an additional year of schooling is estimated to yield 1.3 per cent higher gross hourly wages. Being employed in a skilled or professional occupation is associated with about 30 per cent higher hourly wages, compared to lower level jobs. Adjusting for social class at earlier ages (30 and 26) yields similar results.

\subsubsection{Early Sociability, Self-esteem and Locus of Control}

Another channel through which conscientiousness could affect outcomes is sociability. Being more sociable and having a better social standing is likely to influence success in school or the labour market. Since personality measures could be correlated with early sociability, we incorporate a number of sociability measures into our models.

The Rutter score is a measure of behavioural problems, and is achieved by summing up the scores on 16 mother-rated items. Self-esteem relates to someone's sense of self-worth and confidence. It is constructed by summing up the scores on 12 self-rated items. Locus of control measures whether respondents see the world as deterministic or that an individual can alter outcomes through hard work and effort. The measure for locus of control results from

\footnotetext{
${ }^{15}$ Using a dummy indicator of having achieved one's A-levels rather than years of schooling as a measure for educational achievement yields qualitatively and quantitatively similar results.
} 
adding up the scores of 15 self-rated items. The Rutter, self-esteem, and locus of control scores are standardised to have mean zero and standard deviation one within each regression sample. Sociability at age 16 includes a self-rated amount of sports and number-of-friends indicator, both within and outside school. The Appendix provides details about the individual items and the construction of the measures applied here. Tables A2 and A3 provide descriptive statistics for these measures. ${ }^{16}$

The last three rows of Table 4 present the results of these regression models. Controlling for self-esteem and locus of control does not seem to alter the estimates of measured conscientiousness for wages and other socio-economic outcomes. Including Rutter scores at ages 5,10 and 16 or sociability at age 16 seems to affect the outcomes on the life satisfaction indicators only. ${ }^{17}$

Table A4 reports the coefficients on the other three measured personality traits. While the effects of conscientiousness remain intact after controlling for the home environment, many of the effects for the three other personality measures reduce and often become insignificant. In general, the same holds when we add controls for childhood behaviour problems (Rutter) or sociability at age 16 (Sociability). Controlling for educational achievements or for selfesteem and locus of control at age 10, however, does not alter the associations with outcomes for the other personality traits. Thus, the correlation between personality and adult outcomes is distinct from correlations between these outcomes and education and social class, as well from the associations between measures of early behavioural problems and outcomes.

\subsubsection{Sorting}

Different workers flock to different jobs in the sense that personality is likely to influence a person's occupational choice and match efficiency (e.g., Krueger and Schkade, 2008). We construct measures of occupations from the Standard Occupational Classification of 2000

\footnotetext{
${ }^{16}$ We use measures of self-esteem and locus of control as measured at the age of 10 , but we also derived these measures at age 16. However, we are only able to construct these measures for a limited number of individuals at age 16. The sample is reduced to about 1,100. The estimates remain comparable to the ones we present here.

17 Other age-10 sociability measures considered in our analyses are teacher rated popularity with peers and number of friends, as well as teach rated boldness (as opposed to shyness) and cooperativeness. These are positively associated with wages, but leave our personality estimates unchanged. Other age-16 sociability measures considered are having any hobbies and number of hours spent on them (at 16), having a very close friend and ever having had a boy/girlfriend (at 16), ever having been removed from class, suspended from school, and been in contact with the law (at 16). None of these influence wages if we add them to our main specification, and they also do not affect our personality estimates. The same holds for controlling for age- 16 social outcomes: ever tried cannabis, ever tried cocaine, alcohol consumption, criminal activity and temptation, and being arrested.
} 
(SOC2000) to determine the possible effects of selection into different occupations on our estimates.

Table A5 shows the different categories and demonstrates that people in different occupations differ significantly in terms of personality traits. For example, Science and Technology Professionals score significantly higher than average conscientiousness, agreeableness, and emotional stability at age 16. On the other hand, people becoming Mobile Machine Drivers at age 34 score over half of a standard deviation below average on conscientiousness and agreeableness. These statistics suggest that there is value in analysing the effects of occupational differences in personality traits.

Table 5 shows the results of two models in which we control for average personality traits within occupations. Since the personality of people in different occupations differs, the correlation between conscientiousness and wages drops.

We explore two sets of equations. The first set adds the average personality traits within one's occupation (“Avg Occ. ... (16)"). The second set of estimates does not include the personality trait itself, but a set of dummy variables indicating whether or not the individual scores above the occupational average on each personality trait. For example, to arrive at the dummy "Above Avg Occ. C (16)", we first subtract the average level of conscientiousness in the occupation an individual is employed in from his own conscientiousness at age 16. The dummy indicator is set to one in case the resulting difference is positive, and it is set to zero otherwise. In addition to our main controls, we further control for number of years on the job and add social class dummies to the model. ${ }^{18}$

In column (1) we observe that average occupational personality traits seem to be significant predictors of wages. The effect of individual conscientiousness is much lower, once average conscientiousness within one's occupation is controlled for. The estimate drops from .040 in Table 3 to .016 , and is no longer significantly different from zero, at conventional significance levels. This suggests that much of the estimated wage premium for early conscientiousness could result from occupational sorting.

The final specification, presented in column (2), compares those with below average personality traits to those with above average personality traits. Individuals with traits above

\footnotetext{
${ }^{18} \mathrm{We}$ also conducted the analysis using age-10 information on personality traits. The results are qualitatively similar to the ones presented here.
} 
the occupational average, in terms of conscientiousness, earn on average 4.4 per cent higher gross hourly wages than those below the average, suggesting that even within one's occupation, with a more homogeneous distribution of personality traits, it pays to be more conscientious. This is, however, not the case for the other traits.

\section{Measurement Error}

Measurement error in personality traits could bias our estimated effects of personality traits on outcomes. We deal with possible effects of measurement error in three ways. We reestimate the models documented in Table 3 by using 2SLS, errors-in-variables (EIV) regressions and structural equation modelling (SEM). The results are presented in Table 6; the first-stage estimates of the 2SLS models are displayed in the Appendix (Table A6).

The OLS regressions presented in Table 3 could be biased because of correlation between the independent variables and the error term. The most common way to deal with this problem is to apply an instrumental variables technique. We use the age-10 personality constructs as instruments for those measured at age 16 (see Table 1 for reliability coefficients). We assume that measurement error in the mother-rated items at both points in time is uncorrelated, which seems plausible given the six-year window between the two surveys. The first-stage results shown in Table A6 look fine and the F-tests well exceed the threshold of 10. The predicted traits obtained from the first stage are standardised to have mean zero and standard deviation one, such that the resulting coefficients can be compared with those from the main specifications reported in Table 3. The second-stage estimates are shown in the top panel of Table 6. The coefficients for conscientiousness are generally slightly smaller, and estimated with less precision, which is demonstrated by the lower t-statistics. This is especially true for the measures of life satisfaction, for which the effects of conscientiousness are no longer significantly different from zero. The same pattern of changes exists for the other personality traits. The main exception is the estimated correlation between conscientiousness and wages, which has become stronger, with a point estimate of $.049 .{ }^{19}$

\footnotetext{
${ }^{19}$ As an alternative to using the same mother-rated items at age 10, we consider age-10 personality constructs obtained from teacher-rated items. The first-stage results are strong, and the second-stage estimates again show the same pattern of strong and significant effects for conscientiousness. The precision of the estimates reduces somewhat, with slightly smaller t-statistics. These results are available upon request. Teachers describe the respondents at age 10 by rating them on 53 items, many of which are similar to the items rated by the mothers. After removing items related to motor skills and behavioural problems, a subset of 27 items is used to construct age-10 teacher-rated constructs for conscientiousness (11 items), extraversion (6 items), agreeableness (5 items), and emotional stability (5 items). Cronbach's alphas are $.93, .84, .88$, and .86 , respectively; with the first principal components explaining 58,56,69, and 65 per cent of the variance of the items, respectively.
} 
A second concern with our measures of personality is that the reliability of the four traits differs. A constructed trait less prone to measurement error is more likely to yield significant estimates, which would lead to flaws in our interpretation. To deal with this possibility we use EIV regressions in which Cronbach's alphas (see Table 1) are applied as reliability measures for the traits. The Cronbach's alpha associated with cognitive ability at age 10 is .90 , and is also applied. The second panel of Table 6 presents the estimates. Generally, the coefficients turn out to be similar to the ones presented in Table 3 in terms of statistical significance. The point estimates are generally slightly larger. For conscientiousness we again obtain a higher order of magnitude, with a coefficient of .048 .

Finally, SEM is a maximum likelihood technique to deal with measurement error. It takes into account measurement error at the level of the 22 items we use to construct our four measures of personality traits. More specifically, the errors in the items are part of the estimation procedure and incorporated in the measurement model. The bottom panel in Table 6 shows the estimation results of correcting for measurement error at the item-level. Once again, the pattern of significance is similar to the results from Table 3, with slightly higher estimates, which are measured less precisely. The estimated effect on hourly wages of a standard deviation increase in conscientiousness (.041) is similar to that obtained in Table 3 $(.040)$.

All in all, the predictions in Table 3 do not change substantially when we correct for possible measurement error in the measured traits. The associations found in Table 3 remain significant, even with slightly larger point estimates. In the next sections we therefore continue by using OLS estimators.

\section{Decomposing Conscientiousness}

The estimation results point towards an important role for conscientiousness in explaining outcomes relative to the other personality traits. We continue our analysis with a more detailed decomposition and investigation of the importance of early conscientiousness in explaining outcomes at age 34 .

\subsection{Lower-Order Structure}

Personality psychologists have examined the lower-order structure of conscientiousness and other personality traits. The five most important facets of conscientiousness are impulse control, orderliness, decisiveness, reliability, and industriousness. 


\begin{tabular}{|c|c|c|}
\hline $\begin{array}{l}\text { Facet of } \\
\text { conscientiousness }\end{array}$ & Description & BCS item \\
\hline Impulse control & $\begin{array}{l}\text { "The propensity to inhibit proportional } \\
\text { responses" }\end{array}$ & Easily distracted \\
\hline Orderliness & "The propensity to be organised and neat" & Difficulty concentrating \\
\hline Decisiveness & "The propensity to make deliberate decisions" & Cannot settle \\
\hline Reliability & $\begin{array}{l}\text { "The propensity to be responsible and } \\
\text { dependable" }\end{array}$ & Fails to finish things \\
\hline Industriousness & "The propensity to work hard" & - \\
\hline
\end{tabular}

Investigation of the list of 83 items explored by Roberts et al. (2004) suggests that our items of conscientiousness (see Table 1) can be put into four facets of conscientiousness. The item "cannot settle" falls into the category of decisiveness; "easily distracted" in impulse control; "fails to finish things" in reliability; and "difficulty concentrating" in orderliness. Our database also contains a measure of locus of control, which is related to impulse control. ${ }^{20}$

Table 7 displays correlation coefficients among the four facets of conscientiousness, as well as their correlations with the measured personality traits and outcome variables. Only those coefficients that are significant at the 5 per cent level are shown. Note that positive correlation coefficients indicate that better behaviour is positively associated with the variable at hand. Of these four facets, "fails to finish things" and "easily distracted" show the highest correlations with the conscientiousness construct, as well as with our outcome measures. This is consistent with the observation by Jackson et al. (2009) and Roberts et al. (2004), who also find the strongest outcomes on these two facets of measured conscientiousness in their search for a lower-order structure of personality traits. Locus of control is also statistically significantly correlated with conscientiousness and with the four facets. The correlation coefficients between locus of control and the facets of conscientiousness are much lower compared to the correlations of the four facets with one another, which is consistent with the findings in Table 4. Its correlation with measured emotional stability, pointed at in other studies, is low, relative to its correlation with conscientiousness (e.g., Almlund et al, 2011).

\footnotetext{
${ }^{20}$ Roberts et al. (2004) and Jackson et al. (2009) present an overview of the relevant literature from which the lower-order structure of conscientiousness is derived. Roberts et al. (2004) performed a principal component analysis on 83 items drawn from over 2,000 surveys. It turns out that measured conscientiousness consists of a number of facets. Roberts et al. (2004) find nine facets, Jackson et al. (2009) five. Jackson et al. (2009) find that no existing personality measure includes all facets of conscientiousness identified from the psycholexical search. Roberts et al. (2004) show that there are good levels of discriminant validity with the remaining traits in the Big Five. This allows us to add facets of conscientiousness along with the other three traits (extraversion, agreeableness and neuroticism).
} 


\subsection{Returns to Different Items}

The next step is to add the individual facets of measured conscientiousness to the regression models to see what aspects of conscientiousness explain the various outcomes at age 34 . Table 8 reports the estimates for wages with different sets of controls. Table 9 reports the estimates for the other outcomes for the main specification.

Each column in Table 8 is the result of estimating a specification as shown in Table 4. Each cell refers to a separate analysis in which we have included the individual facets instead of measured conscientiousness. For example, when estimating the wage effect of conscientiousness item "fails to finish things", we regress adult wages on that item, age-16 personality measures extraversion, agreeableness, and emotional stability, and on other controls, depending on the specification used; but we do not include the construct of conscientiousness itself. We have estimated models for the four individual facets of conscientiousness and for locus of control.

Investigation of the rows in Table 8 suggests that the facets "fails to finish things" and "easily distracted" and the trait "locus of control" return significant and sizeable effects on wages. This is true to a lesser extent for the facet "cannot settle", which is insignificant when we control for the home environment or early sociability. The facet "difficulty concentrating", which is related to orderliness, does not seem to be a significant determinant of wages at age 34.

Table 9 reports the estimates of the facets of conscientiousness on the other socio-economic outcomes. The estimates support the results from Table 3. Those who have a higher level of measured conscientiousness at age 16 , are significantly more likely to save, more satisfied with their lives, and less likely to be alcohol dependent, to smoke and to use cannabis.

The facet "cannot settle" is most strongly associated with savings, BMI, smoking and crime. This suggests that more decisive persons are less likely to make mistakes or behave in an unhealthy way. The item "fails to finish things", related to reliability, is significantly associated with more healthy behaviour and higher life satisfaction. The facet "easily distracted" and locus of control, related to impulse control, show similar effects.

In terms of what facets of conscientiousness are important for adult wages, we see that reliability, decisiveness and impulse control when young seem to be relevant. Scoring a standard deviation higher on locus of control at age 16, is associated with 10 per cent higher 
hourly wages at age 34 . The facet of reliability comes close to what personality psychologists have also identified as social responsibility. Roberts and Bogg (2004) show for example that this facet of conscientiousness is a good predictor for adult outcomes related to family, work and substance use. Impulse control is related to the rate of risk aversion used in economics. People who are better able to imagine the consequences of their behaviour experience better outcomes (see Borghans et al., 2008a for a discussion). Becker et al. (2012) obtain similar outcomes for Germany. They show that risk aversion and conscientiousness are correlated, without investigating individual facets. Decisiveness is related to the rate of time preference and self-control. In general, persons with a lower discount rate make less mistakes (unhealthy behaviours, crime) save more and earn higher wages. This is also borne out by the correlations we obtain in Table 9. Moffitt et al. (2011) confirm this result, by showing that children with poor self-control were more likely to make mistakes as adolescents, resulting in poorer health outcomes, a higher probability to become unplanned teenage parents and a higher probability to commit crime.

\section{Changes in Conscientiousness during Childhood}

Many educational programs have been designed to promote educational equity. There is economic value in equalising educational opportunities and achievement for all because underdeveloped human potential burdens economic efficiency. Most programs have been focussing on increasing cognitive ability of poor and disadvantaged children. Heckman et al. (2007) show for example that, while the positive effects on cognitive ability are only shortlived, the Perry preschool program in the United States has produced reductions in teen pregnancy, school dropout, delinquency and work absenteeism. Above, we have presented similar effects of early personality traits on wages, savings, unhealthy behaviours and crime.

From a policy point of view it is now interesting to search for a possible gradient of conscientiousness and its malleability. If a gradient of conscientiousness in outcomes is present, the policymakers' interest should be to investigate whether they can intervene and move people up the gradient. As described in Section 2, Figure 1 plots the averages of the age 34 socio-economic outcomes by the deciles of the age-16 conscientiousness distribution. Less conscientiousness at the age of 16 is associated with lower wages, less savings and lower satisfaction with life by age 34. At the same time, respondents who were more conscientious as children, have a lower body mass index, are less likely to be dependent on alcohol, to smoke or use cannabis regularly, and are less likely to have ever been arrested. These cross- 
sectional patterns reveal the existence of a gradient of conscientiousness worth investigating.

The items we use to construct age-16 conscientiousness, extraversion, agreeableness, and emotional stability are also available at the age of 10 , which allows us to rank respondents on each personality trait at two points in time. Our data do not include an experimental intervention, but we can explore individual changes in the distribution of these traits between ages 10 and 16 to predict socio-economic outcomes. We present two sets of estimates that demonstrate that especially changes in conscientiousness matter for socio-economic outcomes, and that large declines in the distribution of conscientiousness are particularly harmful.

Table 10 shows regression results from adding the change in personality traits between 10 and 16 as covariates, along with the levels of these same traits at age 10. Prior to calculating changes in personality, the factor scores on both age 10 and age 16 personality traits are standardised to have mean zero and standard deviation one, within the sample of respondents with enough information to perform the analysis. This way, we avoid changes in averages and variance in personality due to attrition or selection bias. Besides these personality measures, we include the same controls as used in our main specification (see Table 3).

The pattern of the coefficients on the age-10 personality traits is consistent with that found in Table 3, for the age-16 personality traits. Conditional on the level of the personality traits at age 10 , especially changes in conscientiousness between the ages of 10 and 16 are significant and sizeable explanations for socio-economic outcomes. The change in conscientiousness is predictive of all outcomes, except body mass index and being arrested; that latter being the only outcome significantly affected by changes in emotional stability. The change in extraversion from 10 to 16 is predictive of the same behaviours, and in the same way as age16 extraversion in Table 3. The change in the distribution of extraversion between 10 and 16 is positively associated with the three life satisfaction measures, while also being associated with less saving, more tobacco and cannabis use, and higher rates of arrest.

The estimated effect of a change in conscientiousness on wages .028. This indicates, that a respondent who improved in conscientiousness, from being average at age 10 to scoring one standard deviation above average six years later, earns on average 2.8 per cent higher gross hourly wages at age 34 than an individual scoring the same at age 10 and age 16 on conscientiousness $(C(16)-C(10)=0)$. This hypothetical individual then also has a 3.2 percentage point lower likelihood of being alcohol dependent, a 3.5 percentage point lower 
likelihood to be a smoker, and a 2.2 percentage point lower likelihood to be a regular cannabis user. The results in Table 10 show that it is not only the stock of personality traits at one point in time, but also the development in terms of these traits over time that matter for later life outcomes.

Changes in personality can be both negative and positive, but Table 10 does not allow us to distinguish the effects of rising or falling in the distribution. Second, the results in Table 10 might understate the importance of changes for a number of reasons. First, given that personality measures show high levels of correlation, even at young ages (e.g., Roberts and DelVecchio. 2000), most individuals report only small changes. Even if the distribution of personality traits remains the same, measurement error in our items might lead to small observed changes. If it is further the case that only substantial changes matter for outcomes, the estimates in Table 10 might understate the importance of distributional changes. We therefore explore the effect of large increases and decreases in personality traits between the ages of 10 and 16 .

We distinguish risers and fallers in terms of personality. We consider the top and bottom quartile in terms of changes in personality traits (i.e., C16-C10) as risers and fallers, respectively, with those in the middle representing respondents relatively stable on the trait at hand. Defining stable individuals as those reporting absolute changes smaller than half a standard deviation and defining two dummy variables to indicate either large decreases $(\Delta C<-.5)$ or large increases $(\Delta C>.5)$, fits this approach well, while facilitating comparison and interpretation of coefficients. For conscientiousness, 56 per cent of respondents reports absolute changes smaller than half a standard deviation. For agreeableness and emotional stability this share is 48 per cent, and it is 41 per cent for extraversion. For each trait, risers and fallers are (by construction) equally distributed among the remaining respondents.

Table 11 presents the estimates of this approach. The estimates suggest that the importance of changes in personality for adult wages is more likely to be associated with a decrease in personality during childhood. Only 7 out of 50 rise dummies are significant at the 10 per cent level, which is at chance level. On the other hand, the same holds for 16 out of 50 fall dummies. For conscientiousness, a large decline in the distribution is significantly associated with all ten socio-economic outcomes, whereas a rise is not significantly associated with any of these outcomes. Compared to someone stable in terms of all four traits, an individual that 
experienced a large decline in conscientiousness between ages 10 and 16 earns 5.5 per cent lower gross hourly wages. The likelihood of being an alcoholic, a smoker, or a cannabis user is also higher (5.7, 8.3 and 5.5 percentage points higher, respectively), and the individual is also 3.4 percentage points more likely to have ever been arrested. Given that 18 per cent of our working sample is alcohol dependent, 26 per cent are smokers, 15 per cent use cannabis regularly, and 14 per cent have been arrested, these effects are quite substantial.

These results suggest that policymakers could be most effective in preventing children from falling behind. However, personality at age 10 also has predictive value, which points to the importance of stimulation of developing traits and conscientiousness more specifically.

\section{Conclusion}

This research has presented an analysis of correlations between early measures of personality traits and adult outcomes using data from several waves of the 1970 British Cohort Study. Our main findings suggest that early conscientiousness is correlated with adult wages and other socio-economic outcomes. Controlling for a number of measures related to the childhood home environment, sociability and educational achievement does not alter this result. In addition, measurement error does not seem to plague our estimates, since three different types of analyses to deal with measurement error do not substantially change the results. A substantial share of the conscientiousness wage premium is likely to stem from sorting into occupations, while within occupations it still pays to have higher conscientiousness. Investigating other measures and structures of personality suggests that impulse control, decisiveness and reliability are among the most important facets of conscientiousness in explaining outcomes. These facets can be related to economic parameters such as risk aversion, social preferences and time preference.

Our findings are consistent with previous research that suggests that differences in personality traits are important in explaining differences in outcomes. We know that cognitive ability and low social class origins are hard to improve through intervention programmes. In addition, looking at our gradient of conscientiousness, it turns out that conscientiousness is heterogeneous and a determinant of socio-economic outcomes. From a policy point of view it seems beneficial to prevent children from falling behind in their development throughout childhood.

Further research by economists and psychologists is necessary. Borghans et al. (2008a) 
present a research agenda for economists and Roberts (2009) presents suggestions for improvement for psychologists. This paper has taken up a small part of this agenda, but a deeper understanding of the interactions between early traits and adult outcomes seems relevant. Also, the interplay with the home environment, school and different states of a child and his later outcomes is not well-understood. Finally, dealing with measurement error in traits remains an important direction for improvement and further research. Both theoretical and empirical effort is required to make progress and to be able to design effective policies.

\section{References}

Almlund, M., Duckworth, A.L., Heckman, J. J. \& Kautz, T. (2011). Personality Psychology and Economics. IZA Discussion Paper No. 5500.

Antecol, H. \& Cobb-Clark, D.A. (2010). Do non-cognitive skills help explain the occupational segregation of young people? IZA Discussion Paper No. 5093.

Becker, A., Deckers, T., Dohmen, T., Falk, A. \& Kosse, F. (2012). The Relationship Between Economic Preferences and Psychological Personality Measures. IZA Discussion Paper No. 6470.

Borghans, L., ter Weel, B. \& Weinberg, B. A. (2006). People People: Social Capital and the Labor-Market Outcomes of Underrepresented Groups. NBER Working Paper No. 11985.

Borghans, L., Duckworth, A. L., Heckman, J. J., \& ter Weel, B. (2008a). The Economics and Psychology of Personality Traits. Journal of Human Resources, 43(4), 972-1059.

Borghans, L., Meijers, H., \& ter Weel, B. (2008b). The Role of Noncognitive Skills in Explaining Cognitive Test Scores. Economic Inquiry, 46(1), 2-12.

Borghans, L., ter Weel, B. \& Weinberg, B. A. (2008c). Interpersonal Styles and Labor Market Outcomes. Journal of Human Resources, 43(4), 815-858.

Buchsbaum, D., Buchanan, R., Centor, R., Schnoll, S. \& Lawton, M. (1991). Screening for alcohol abuse using CAGE scores and likelihood ratios. Annals of Internal Medicine, 115(10), 774-777.

Cobb-Clark, D. A. \& Schurer, S. (2013). Two economists' musings on the stability of locus of control. Economic Journal, forthcoming.

Cobb-Clark, D. A. \& Tan, M. (2011). Noncognitive skills, occupational attainment, and relative wages. Labour Economics, 18(1), 1-13.

Cunha, F., \& Heckman, J. (2007). The Technology of Skill Formation. American Economic Review, 97(2), 31-47.

Cunha, F., \& Heckman, J. J. (2008). Formulating, Identifying and Estimating the Technology of Cognitive and Noncognitive Skill Formation. Journal of Human Resources, 43(4), 738-782.

Cunha, F., Heckman, J. J., Lochner, L., \& Masterov, D. (2006). Interpreting the Evidence on Life Cycle Skill Formation. In E. Hanushek and F. Welch (eds.): Handbook of the Economics of Education (pp. 697-812).

Cunha, F., Heckman, J. J., \& Schennach, S. M. (2010). Estimating the Technology of Cognitive and Noncognitive Skill Formation. Econometrica, 78(3), 883-931.

Currie, J. \& Stabile, M. (2006). Child Mental Health and Human Capital Accumulation: The Case of ADHD. Journal of Health Economics, 25(6), 1094-1118.

Daly, M., Delaney, L. and Harmon, C. P. (2009). Psychological and Biological Foundations of Time Preferences. Journal of the European Economic Association, 7(2-3), 659-669. 
Dohmen T., Falk A., Huffman D. \& Sunde U. (2010). Are Risk Aversion and Impatience Related to Cognitive Ability? American Economic Review, 100(4), 1238-1260.

Doyle, O., Harmon, C. P., Heckman, J. J., \& Tremblay, R. E. (2009). Investing in Early Human Development: Timing and Economic Efficiency. Economics and Human Biology, 7(1), 1-6.

Fehr, E. (2009) On the Economics and Biology of Trust. Journal of the European Economic Association, 7(1), 235-266.

Filer, R. K. (1983). Sexual Differences in Earnings: The Role of Individual Personalities and Tastes. Journal of Human Resources, 18(1), 82-99.

Frederick S., Loewenstein G. \& O'Donoghue T. (2002). Time Discounting and Time Preference: A Critical Review. Journal of Economic Literature, 40(2), 351-401.

Goldberg, L. R. (1993). The Structure of Phenotypic Personality Traits. American Psychologist, 48(1), 26-34.

Gronau, R. (1974). Wage Comparisons: A Selectivity Bias. Journal of Political Economy, 82(6), 1119-1143.

Grove, W. A., Hussey, A. \& Jetter, M. (2011). The Gender Pay Gap Beyond Human Capital: Heterogeneity in Noncognitive Skills and in Labor Market Tastes. Journal of Human Resources, 46(4), 827-874.

Heckman, J. J. (2007). The Economics, Technology, and Neuroscience of Human Capability Formation. Proceedings of the National Academy of Sciences of the United States of America, 104(33), 13250-13255.

Heckman, J. J., Malofeeva, L., Pinto, R. R. \& Savelyev, P. (2007). The Effect of the Perry Preschool Program on the Cognitive and Noncognitive Skills of its Participants. University of Chicago, Working Paper.

Heckman, J. J., Stixrud, J., \& Urzua, S. (2006). The Effects of Cognitive and Noncognitive Abilities on Labor Market Outcomes and Social Behavior. Journal of Labor Economics, 24(3), 411-482.

Herrnstein, R. J., \& Murray, C. A. (1994). The Bell Curve: Intelligence and Class Structure in American Life. New York, NY US: Free Press.

Jackson, J. J., Bogg, T., Walton, K. E., Wood, D., Harms, P. D., Lodi-Smith, J., et al. (2009). Not All Conscientiousness Scales Change Alike: A Multimethod, Multisample Study of Age Differences in the Facets of Conscientiousness. Journal of Personality and Social Psychology, 96(2), 446-459.

John, O. P., \& Srivastava, S. (1999). The Big Five Trait Taxonomy: History, Measurement, and Theoretical Perspectives. In L. A. Pervin \& O. P. John (Eds.), Handbook of personality: Theory and research (2nd ed.). (pp. 102-138). New York, NY US: Guilford Press.

King, M. (1986). At risk drinking among general practice attenders: validation of the CAGE questionnaire. Psychological Medicine, 16(1), 213-217.

Knudsen, E. I., Heckman, J. J., Cameron, J. L., \& Shonkoff, J. P. (2006). Economic, neurobiological, and Behavioral Perspectives on Building America's Future Workforce. Proceedings of the National Academy of Sciences of the United States of America, 103(27), 10155-10162.

Krueger, A. B., \& Schkade, D. (2008). Sorting in the Labor Market. Journal of Human Resources, 43(4), 859-883.

Lebel, C., \& Beaulieu, C. (2011). Longitudinal Development of Human Brain Wiring Continues from Childhood into Adulthood. The Journal of Neuroscience, 31(30), 10937-10947.

McCrae, R. R., \& Costa, P. T. (1994). The Stability of Personality: Observation and Evaluations. Current Directions in Psychological Science, 3(6), 173-175. 
McCrae, R. R., \& John, O. P. (1992). An Introduction to the Five-Factor Model and its Applications. Journal of Personality, 60(2), 175-215.

Moffitt, T. E., Arseneault, L., Belsky, D., Dickson, N., Hancox, R. J., Harrington, H., et al. (2011). A Gradient of Childhood Self-Control Predicts Health, Wealth, and Public Safety. Proceedings of the National Academy of Sciences of the United States of America, 108(7), 2693-2698.

Mueller, G., \& Plug, E. (2006). Estimating the Effect of Personality on Male and Female Earnings. Industrial and Labor Relations Review, 60(1), 3-22.

Persico, N., Postlewaite, A., \& Silverman, D. (2004). The Effect of Adolescent Experience on Labor Market Outcomes: The Case of Height. Journal of Political Economy, 112(5), 1019-1053.

Roberts, B. W. (2009). Back to the Future: Personality and Assessment and Personality Development. Journal of Research in Personality, 43(2), 137-145.

Roberts, B. W., \& Bogg, T. (2004). A Longitudinal Study of the Relationships Between Conscientiousness and the Social- Environmental Factors and Substance-Use Behaviors That Influence Health. Journal of Personality, 72(2), 325-353.

Roberts, B. W., Bogg, T., Walton, K. E., Chernyshenko, O. S., \& Stark, S. E. (2004). A Lexical Investigation of the Lower-Order Structure of Conscientiousness. Journal of Research in Personality, 38(2), 164-178.

Roberts, B. W., \& DelVecchio, W. F. (2000). The Rank-Order Consistency of Personality Traits From Childhood to Old Age: A Quantitative Review of Longitudinal Studies. Psychological Bulletin, 126(1), 3-25.

Roberts, B. W., Wood, D., \& Caspi, A. (2008). The Development of Personality Traits in Adulthood. In O. P. John, R. W. Robins \& L. A. Pervin (Eds.), Handbook of personality: Theory and research (3rd ed.). (pp. 375-398). New York, NY US: Guilford Press.

Schweinhart, L.J., Montie, J., Xiang, Z., Barnett, W.S., Belfield, C.R., \& Nores, M. (2005). Lifetime Effects: The High/Scope Perry Preschool Study through Age 40. Ypsilanti, MI: High/Scope Press.

Shonkoff, J. P., \& Phillips, D. A. (2000). From Neurons to Neighborhoods: The Science of Early Childhood Development. Washington, DC US: National Academy Press.

Social Statistics Research Unit (SSRU) (1986). BCS70 - The 1970 British Cohort Study: The Sixteen-year Follow-up. A Guide to the BCS70 16 Year Data.

Sutter, M., Kocher, M. G. Rutzler, D. \& Trautmann, S. T. (2012). Impatience and Uncertainty: Experimental Decisions Predict Adolescents' Field Behavior. American Economic Review, forthcoming.

Webb, E. (1915). Character and Intelligence. British Journal of Psychology, 1(3). 


\begin{tabular}{|c|c|c|c|c|}
\hline & Conscientiousness & Extraversion & Agreeableness & Emotional Stability \\
\hline \# items & 4 & 5 & 7 & 6 \\
\hline Items & $\begin{array}{l}\text { cannot settle } \\
\text { easily distracted } \\
\text { fails to finish things } \\
\text { difficulty concentrating }\end{array}$ & $\begin{array}{l}\text { not much liked } \\
\text { worried } \\
\text { solitary } \\
\text { afraid of new } \\
\text { fussy/over-particular }\end{array}$ & $\begin{array}{l}\text { destroys belongings } \\
\text { fights with others } \\
\text { takes others' things } \\
\text { disobedient } \\
\text { tells lies } \\
\text { bullies others } \\
\text { interferes with others }\end{array}$ & $\begin{array}{l}\text { irritable } \\
\text { miserable/distressed } \\
\text { requests must be met } \\
\text { sullen or sulky } \\
\text { changes mood quickly } \\
\text { outbursts of temper }\end{array}$ \\
\hline \multicolumn{5}{|l|}{ Age 10} \\
\hline Explained variance: & $66.07 \%$ & $37.84 \%$ & $48.12 \%$ & $53.48 \%$ \\
\hline $\begin{array}{l}\text { Cronbach's alpha: } \\
n=12,666\end{array}$ & .83 & .58 & .81 & .82 \\
\hline \multicolumn{5}{|c|}{ Age 10 (with imputed values if missing 1 or 2 out of 22 items) } \\
\hline Explained variance: & $65.89 \%$ & $37.64 \%$ & $48.00 \%$ & $53.28 \%$ \\
\hline $\begin{array}{l}\text { Cronbach's alpha: } \\
n=13,301\end{array}$ & .82 & .58 & .81 & .82 \\
\hline Age 16 & & & & \\
\hline Explained variance: & $65.17 \%$ & $37.39 \%$ & $44.66 \%$ & $56.49 \%$ \\
\hline $\begin{array}{l}\text { Cronbach's alpha: } \\
n=7,669\end{array}$ & .81 & .57 & .77 & .84 \\
\hline \multicolumn{5}{|c|}{ Age 16 (with imputed values if missing 1 or 2 out of 22 items) } \\
\hline Explained variance: & $65.41 \%$ & $37.38 \%$ & $45.35 \%$ & $56.53 \%$ \\
\hline $\begin{array}{l}\text { Cronbach's alpha: } \\
n=8,566\end{array}$ & .81 & .57 & .78 & .84 \\
\hline
\end{tabular}


Table 2. Correlations of Personality with Socio-Economic Outcomes

\begin{tabular}{lcccc}
\hline \hline & $\mathbf{C}$ & $\mathbf{E}$ & $\mathbf{A}$ & $\mathbf{~ N}$ \\
\hline Personality & & & & \\
(C) Conscientiousness (16) &. & .26 & .48 & .49 \\
(E) Extraversion (16) & .26 & 1.00 & .24 & .43 \\
(A) Agreeableness (16) & .48 & .24 &. & .55 \\
(N) Emotional Stability (16) & .49 & .43 & .55 &. \\
& & & & \\
Outcomes & & & & \\
Wage & .15 & .05 & .11 & .12 \\
Save & .12 &. & .09 & .09 \\
BMI & -.09 &. & -.08 & -.04 \\
Alcoholic & -.05 &. &. &. \\
Smoke & -.17 &. & -.17 & -.11 \\
Cannabis & -.08 &. & -.09 & -.04 \\
Arrested & -.13 & .04 & -.15 & -.07 \\
Satisfaction & .12 & .10 & .10 & .10 \\
Life Get & .16 & .12 & .11 & .11 \\
Life Run & .11 & .09 & .10 & .08 \\
\hline Nit Con & & & .10
\end{tabular}

Note: Correlation coefficients. Only those significant at the 5 per cent level or higher are reported. The sample applied is our working sample of 2,934 individuals with valid information on adult wages, age-10 cognitive ability, and age-16 personality. 
Figure 1. Socio-Economic Outcomes by Deciles of Conscientiousness
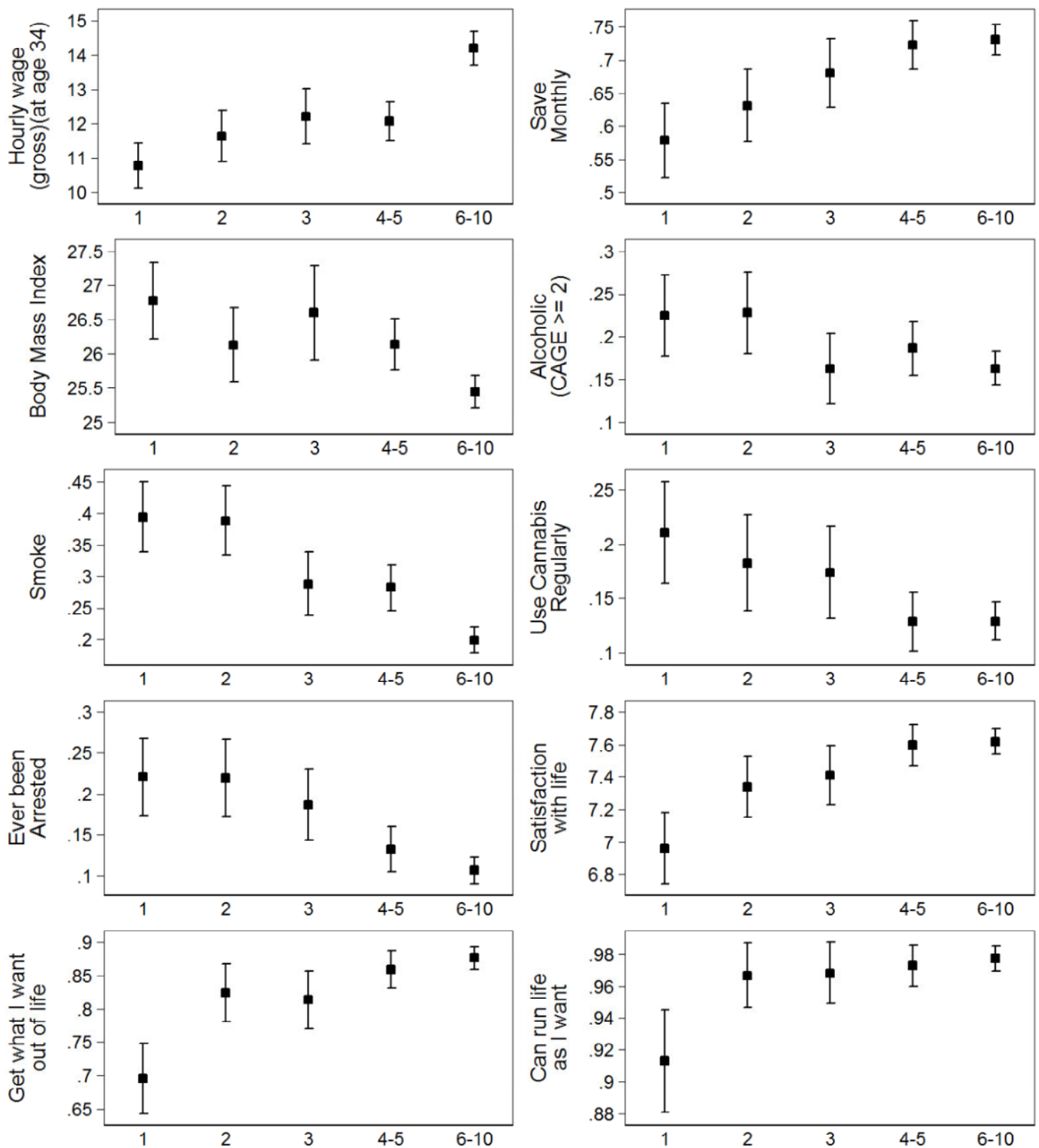

Means and 95\% Upper and Lower Limits (vertical axis) by deciles of age 16 Conscientiousness (horizontal axis)

Note: Averages and 95 per cent confidence intervals of socio-economic outcomes by deciles of age-16 conscientiousness; The upper deciles 4 and 5, and 6 through 10, are grouped together since we cannot discriminate between them due to the limited range of the scale on conscientiousness. The sample applied is our working sample of 2,934 individuals with valid information on adult wages, age-10 cognitive ability, and age-16 personality. 


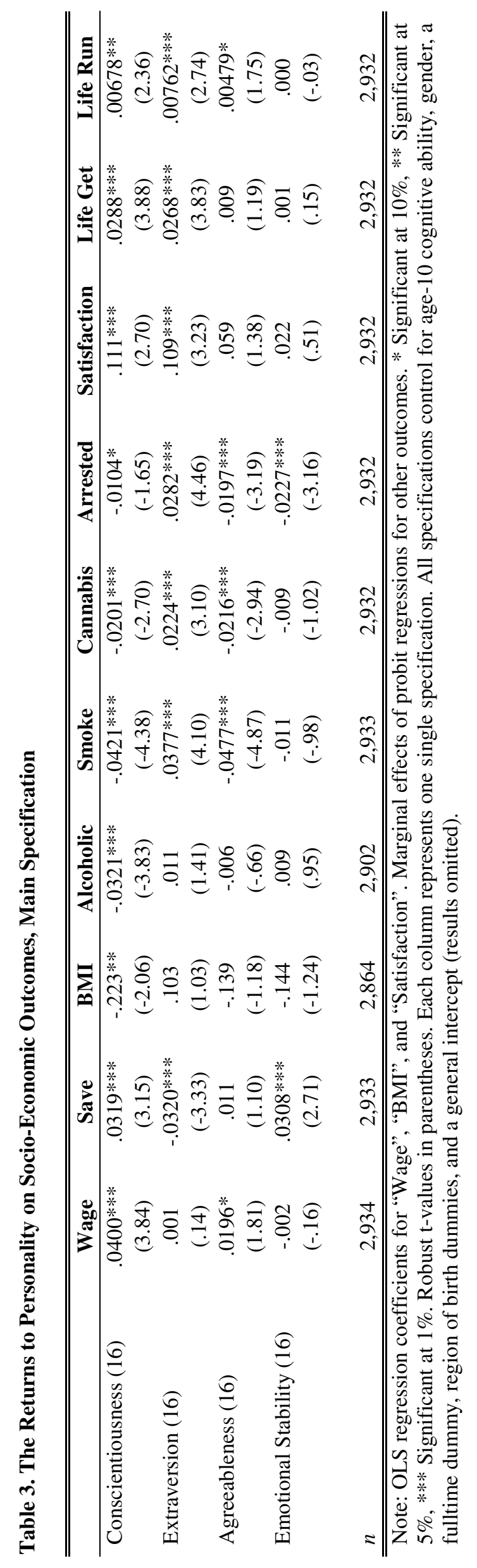




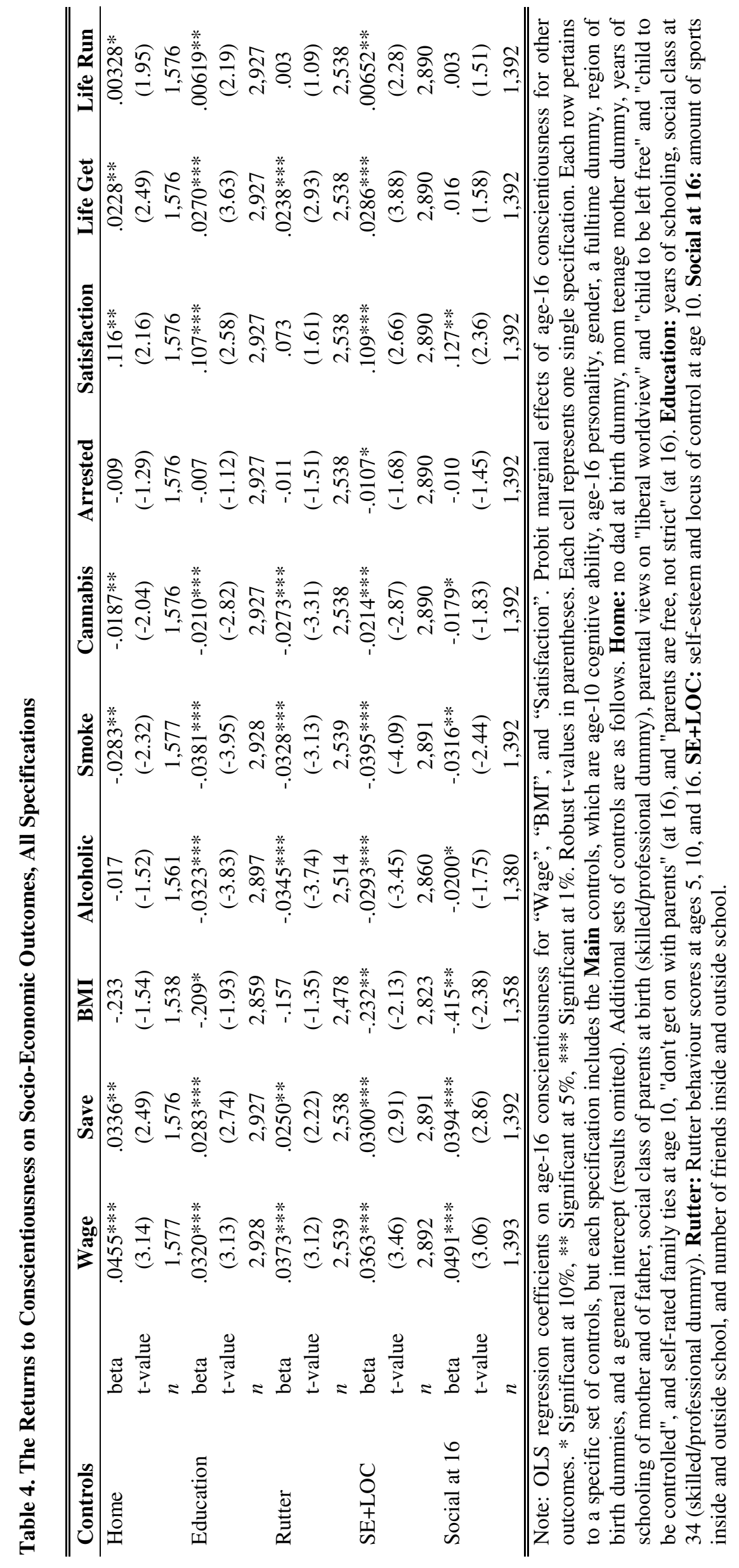


Table 5. The Returns to Personality on Wages, Controlling for Occupational Sorting

\begin{tabular}{|c|c|c|}
\hline & (1) & (2) \\
\hline Conscientiousness (16) & $\begin{array}{c}.016 \\
(1.63)\end{array}$ & \\
\hline Extraversion (16) & $\begin{array}{l}.008 \\
(.87)\end{array}$ & \\
\hline Agreeableness (16) & $\begin{array}{l}.008 \\
(.79)\end{array}$ & \\
\hline Emotional Stability (16) & $\begin{array}{l}-.002 \\
(-.13)\end{array}$ & \\
\hline Avg Occ. Conscientiousness (16) & $\begin{array}{c}.573 * * * \\
(5.93)\end{array}$ & \\
\hline Avg Occ. Extraversion (16) & $\begin{array}{c}.147 \\
(1.57)\end{array}$ & \\
\hline Avg Occ. Agreeableness (16) & $\begin{array}{c}-.357 * * * \\
(-3.21)\end{array}$ & \\
\hline Avg Occ. Emotional Stability (16) & $\begin{array}{c}.267 * * * \\
(3.02)\end{array}$ & \\
\hline Above Avg Occ. C (16) & & $\begin{array}{c}.0430 * * \\
(2.19)\end{array}$ \\
\hline Above Avg Occ. E (16) & & $\begin{array}{c}.026 \\
(1.41)\end{array}$ \\
\hline Above Avg Occ. A (16) & & $\begin{array}{l}-.008 \\
(-.37)\end{array}$ \\
\hline Above Avg Occ. N (16) & & $\begin{array}{l}-.008 \\
(-.40)\end{array}$ \\
\hline$n$ & 2,913 & 2,913 \\
\hline R-squared & .338 & .321 \\
\hline
\end{tabular}

Note: OLS regression coefficients with log hourly wage at age 34 as the dependent variable. $*$ Significant at $10 \%, * *$ Significant at 5\%, *** Significant at 1\%. Robust t-values in parentheses. All specifications control for age-10 cognitive ability, gender, a fulltime dummy, tenure in current job, social class dummies, region of birth dummies, and a general intercept (results omitted). Respondents are grouped in occupations using the first two digits of the SOC2000. Column (1) uses averages of age-16 personality traits by occupation alongside individual scores on the same traits. Column (2) uses four dummy variables, one for each trait, indicating whether an individual scores above or below his/her occupation average on that trait. 


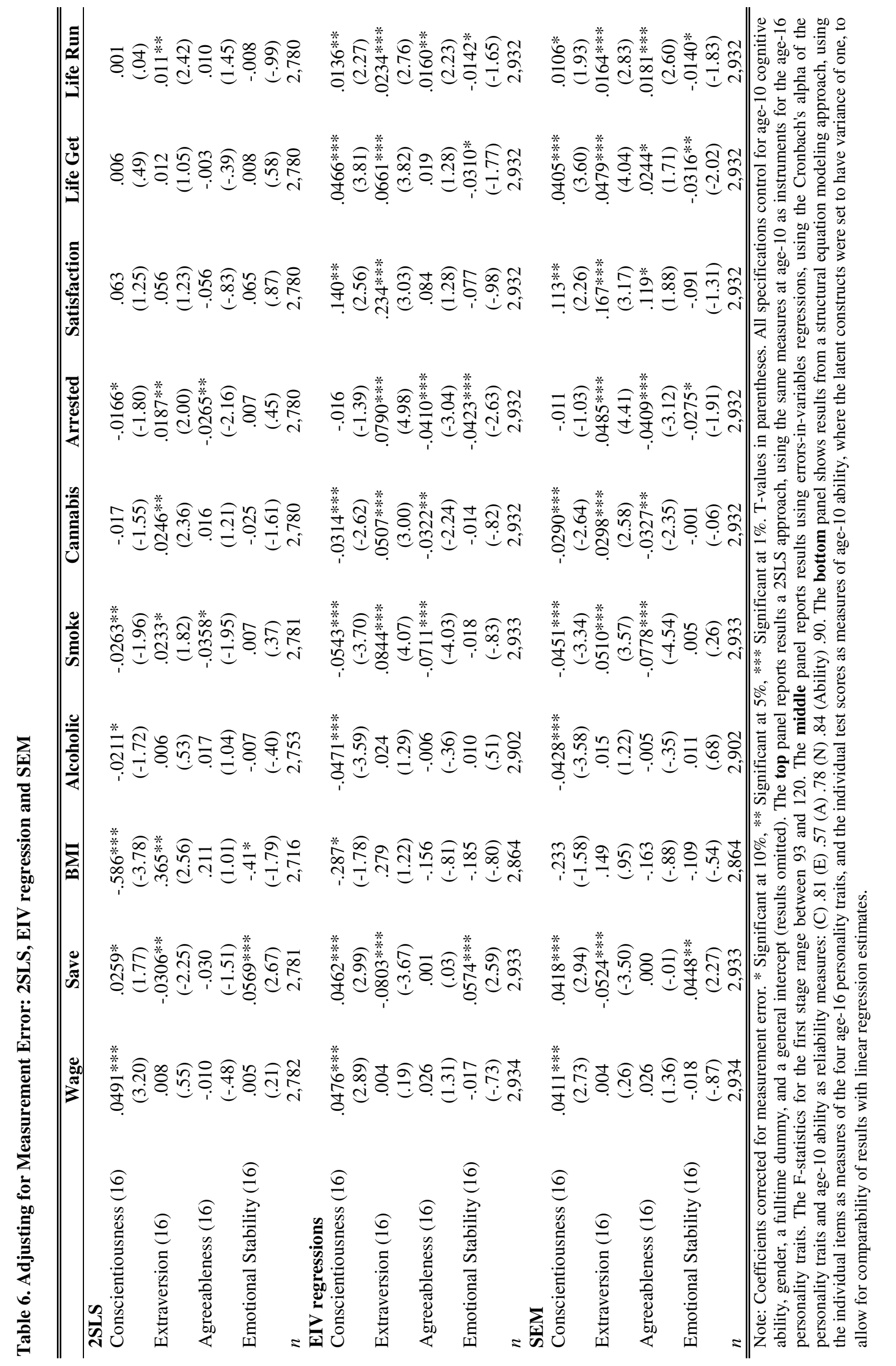


Table 7. Correlations of Conscientiousness Items with Personality and Socio-Economic Outcomes

\begin{tabular}{|c|c|c|c|c|c|}
\hline & $(\mathrm{C} 1)$ & $(\mathrm{C} 2)$ & (C3) & (C4) & (loc) \\
\hline \multicolumn{6}{|l|}{ Conscientiousness items } \\
\hline (C1) fails to finish things (reliability) & $\cdot$ & .57 & .57 & .52 & .21 \\
\hline (C2) easily distracted (impulse control) & .57 & $\cdot$ & .49 & .47 & .28 \\
\hline (C3) difficulty concentrating (orderliness) & .57 & .49 & $\cdot$ & .47 & .19 \\
\hline (C4) cannot settle (decisiveness) & .52 & .47 & .47 & $\cdot$ & .19 \\
\hline (loc) Locus of control (16) (impulse control) & .21 & .28 & .19 & .19 & $\cdot$ \\
\hline \multicolumn{6}{|l|}{ Personality constructs } \\
\hline (C) Conscientiousness (16) & .84 & .80 & .79 & .76 & .28 \\
\hline (E) Extraversion (16) & .17 & .20 & .22 & .23 & .09 \\
\hline (A) Agreeableness (16) & .39 & .42 & .32 & .40 & .22 \\
\hline (N) Emotional Stability (16) & .40 & .40 & .37 & .38 & .23 \\
\hline \multicolumn{6}{|l|}{ Outcomes } \\
\hline Wage & .14 & .14 & .10 & .11 & .32 \\
\hline Save & -.07 & -.08 & -.05 & -.10 & -.10 \\
\hline BMI & .11 & .09 & .09 & .10 & .19 \\
\hline Alcoholic & .11 & .11 & .08 & .10 & .15 \\
\hline Smoke & -.06 & -.04 & -.04 & . & . \\
\hline Cannabis & -.16 & -.16 & -.08 & -.13 & -.19 \\
\hline Arrested & -.09 & -.08 & -.05 & -.04 & . \\
\hline Satisfaction & -.10 & -.13 & -.08 & -.11 & -.12 \\
\hline Life Get & .15 & .12 & .11 & .11 & .16 \\
\hline Life Run & .09 & .08 & .10 & .08 & .10 \\
\hline
\end{tabular}

Note: Correlation coefficients. Only those significant at the 5 per cent level or higher are reported. Although formulated negatively, each item is scaled such that higher scores are more desirable. Locus of control is standardised (mean 0, st.dev. 1) and higher scores indicate higher internal locus of control. The sample applied is our working sample of 2,934 individuals with valid information on adult wages, age-10 cognitive ability, and age-16 personality. 
Table 8. The Returns to Conscientiousness Items on Wages, All Specifications

\begin{tabular}{|c|c|c|c|c|c|c|}
\hline Controls & Main & Home & Education & Rutter & SE+LOC & Social at 16 \\
\hline (C1) fails to finish things & $.0624 * * *$ & $.0940 * * *$ & $.0529 * * *$ & $.0647 * * *$ & $.0576 * * *$ & $.0929 * * *$ \\
\hline (reliability) & (4.12) & $(3.94)$ & $(3.52)$ & $(3.77)$ & $(3.77)$ & $(3.56)$ \\
\hline R-squared & .215 & .231 & .248 & .214 & .224 & .236 \\
\hline (C2) easily distracted & $.0470 * * *$ & $.0654 * * *$ & $.0348 * *$ & $.0493 * * *$ & $.0415 * * *$ & $.0669 * * *$ \\
\hline (impulse control) & $(3.25)$ & (3.10) & $(2.45)$ & $(3.06)$ & $(2.83)$ & $(2.95)$ \\
\hline R-squared & .214 & .227 & .246 & .212 & .222 & .233 \\
\hline (C3) difficulty concentrating & .019 & .011 & .016 & .004 & .016 & .028 \\
\hline (orderliness) & $(1.12)$ & $(.43)$ & $(.92)$ & $(.21)$ & $(.89)$ & $(1.02)$ \\
\hline R-squared & .211 & .222 & .244 & .209 & .22 & .228 \\
\hline (C4) cannot settle & $.0547 * * *$ & .040 & $.0426 * *$ & $.0488 *$ & $.0521 * *$ & .038 \\
\hline (decisiveness) & $(2.65)$ & $(1.37)$ & $(2.11)$ & $(1.80)$ & $(2.49)$ & $(1.19)$ \\
\hline R-squared & .212 & .223 & .245 & .21 & .221 & .228 \\
\hline$n$ & 2,934 & 1,577 & 2,928 & 2,539 & 2,892 & 1,393 \\
\hline (loc) Locus of control (16) & $.0967 * * *$ & $.0849 * * *$ & $.0774 * * *$ & $.0970 * * *$ & $.0864 * * *$ & $.0918 * * *$ \\
\hline (impulse control) & $(7.75)$ & $(6.10)$ & $(6.32)$ & $(7.30)$ & $(6.83)$ & $(6.35)$ \\
\hline$n$ & 1,634 & 1,336 & 1,631 & 1,423 & 1,610 & 1,219 \\
\hline R-squared & .244 & .248 & .28 & .243 & .25 & .253 \\
\hline
\end{tabular}

Note: OLS regression coefficients with log hourly wage at age 34 as the dependent variable. $*$ Significant at $10 \%$, ** Significant at 5\%, *** Significant at 1\%. Robust t-values in parentheses. Each cell represents one single specification. Each row reports results of using that item, rather than the construct of conscientiousness, in the set of personality traits. Although formulated negatively, each item is scaled such that higher scores are more desirable: 1 "totally applies", 2 "applies somewhat", 3 "does not apply". Locus of control is standardised (mean 0, st.dev. 1) within each regression sample and higher scores indicate higher internal locus of control. Each column pertains to a specific set of controls, but each specification includes the Main controls, which are age-10 cognitive ability, age-16 extraversion, agreeableness, and emotional stability, gender, a fulltime dummy, region of birth dummies, and a general intercept (results omitted). Additional sets of controls are as follows. Home: no dad at birth dummy, mom teenage mother dummy, years of schooling of mother and of father, social class of parents at birth (skilled/professional dummy), parental views on "liberal worldview" and "child to be left free" and "child to be controlled", and self-rated family ties at age 10, "don't get on with parents" (at 16), and "parents are free, not strict" (at 16). Education: years of schooling, social class at 34 (skilled/professional dummy). Rutter: Rutter behaviour scores at ages 5, 10, and 16. SE+LOC: self-esteem and locus of control at age 10. Social at 16: amount of sports inside and outside school, and number of friends inside and outside school. 


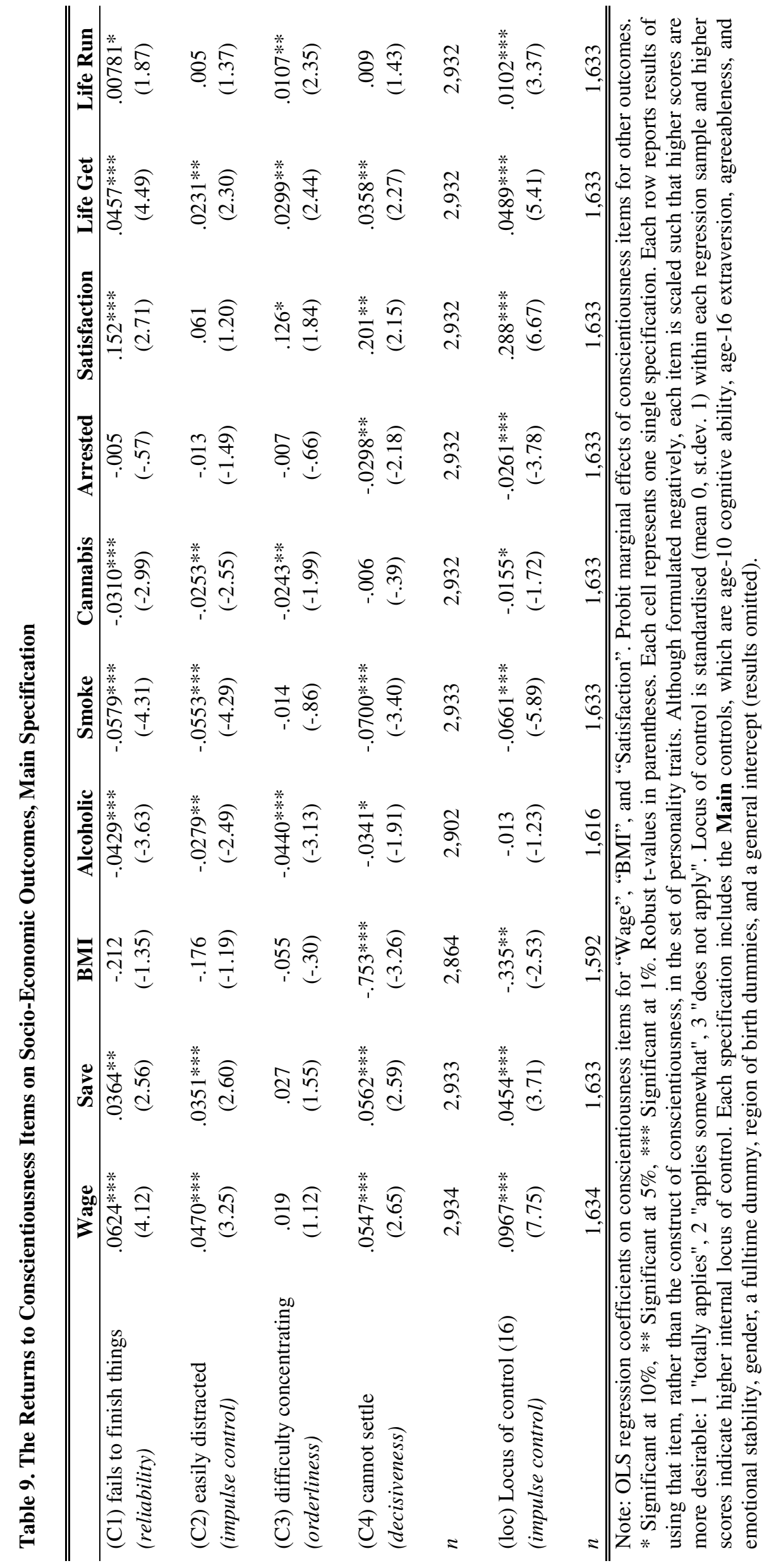




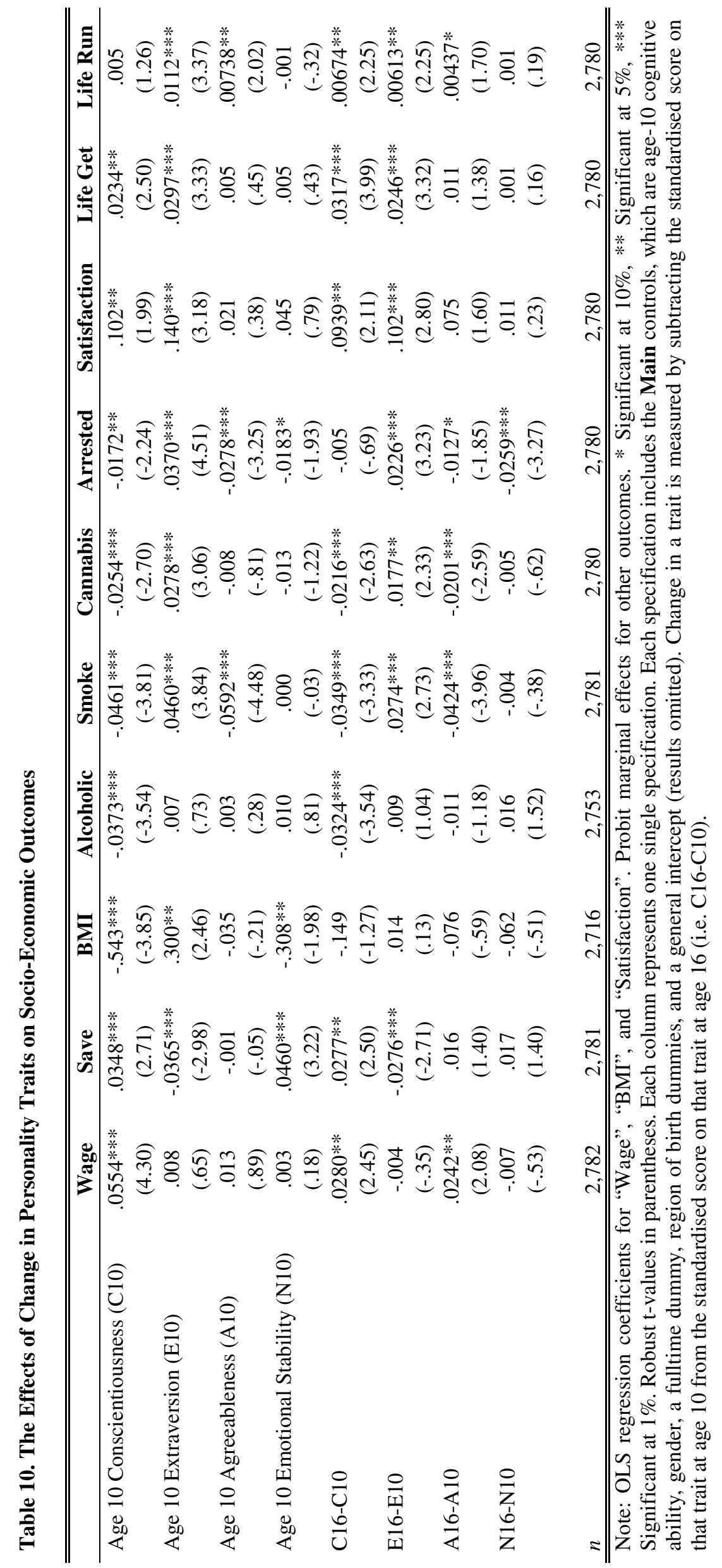




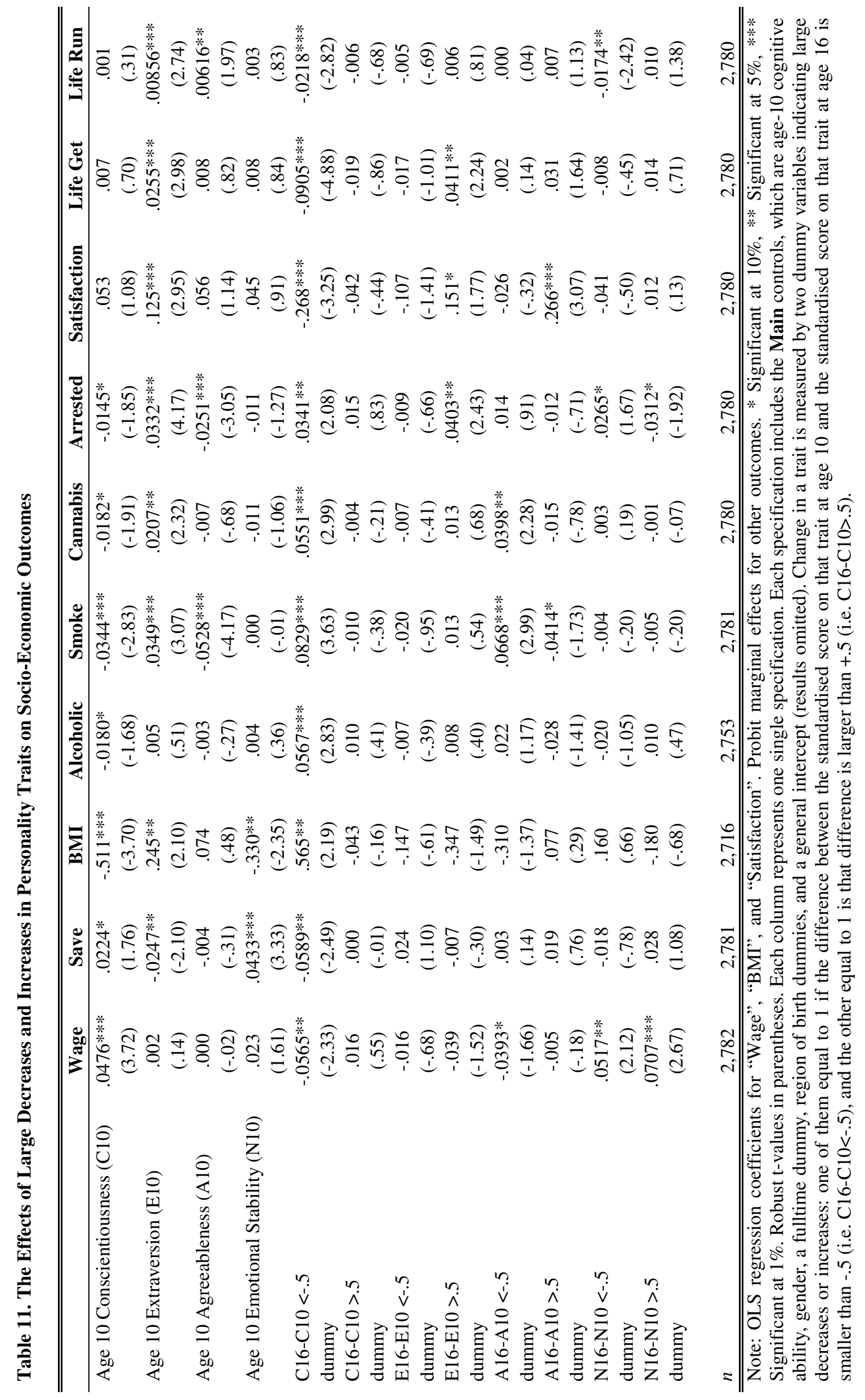

ले 


\section{Appendix}

This appendix presents supporting materials. All data come from the 1970 British Cohort Study. The 1970 British Cohort Study began by collecting data on births and families of all children born in Great Britain in a particular week in April of 1970. These children/respondents were then followed and reinterviewed roughly every 4 or 5 years over the course of their life. Of the initial 17,196 babies born in 1970, 9,665 respondents remain in 2004. After selecting employed individuals with valid information on wages, childhood ability and personality, we retain a working sample of 2,937 respondents used for the analyses in this research. In Section A1 we show the details of the cluster analysis and principal component analysis used to construct the personality measures related to the Big Five inventory. Section A2 provides details on the items used to construct our sociability measures: the Rutter behaviour scores, self-esteem, and locus of control.

Table A1 describes the core variables used in this study. The table consists of six sets of variables. First, the outcome variables at age 34 are presented. The next set consists of our personality measures (covered in more detail in the next section), and is followed by sets of variables relating to the home environment, educational achievement, early sociability, and occupational sorting. The variables in Table A2 and Table A3 are set up in the same order. Table A2 presents a number of descriptive statistics for these sets of variables, both for the working sample used in all analyses in this paper, as well as for the unrestricted sample. Table A3 provides averages for all variables for those scoring above and below average on our age-16 personality measures. Table A4 provides the coefficients for the traits extraversion, agreeableness, and emotional stability that belong to the analyses reported on in Table 4. Table A5 displays the grouping of respondents in occupations and associated average personality traits, which is used for the analysis reported on in Table 5.

\section{A1 Personality Measures}

A Big Five-type taxonomy of personality would allow us to capture the relative importance of different dimensions of an individual's personality. The BCS70 offers a number of alternatives, although these sets of items do not offer items to capture openness. Hence, we are able to construct measures capturing a child's conscientiousness, extraversion, agreeableness, and emotional stability (neuroticism).

At age 10, the teachers of the respondents are asked to complete a set of 53 items on the child's developmental behaviours, of which we retain 27 items to construct a teacher rated Big 4 taxonomy of personality. At age 16, respondents themselves fill in a set of 27 items under the heading "Knowing Myself", 18 of which can be used to construct measures for each of the Big 5, although the strength of the construct for openness is rather weak. Since these two sets of items are not the same, and rated by different people, we prefer a third set of items that the BCS70 offers: a set of 38 parent-rated items, available at age 10 as well as age 16. A cluster analysis of a subsample of 22 of these items (excluding items related to fine and gross motor skills) shows the expected grouping of items into four clusters, representing conscientiousness, extraversion, agreeableness, and emotional stability (See Figure A1).

An additional benefit of using the set of mother-rated items is that this set contains more valid observations, both at ages 10 and 16. To further increase the number of observations, we impute missing values for individuals that miss 1 or 2 of the 22 items used for constructing our personality measures. We apply multiple imputation through chained equations using the remaining 21 items as predictors for the item of interest. By doing so, we increase the number of observations with valid age-10 personality measures by over 5 per cent (from 6,493 to 6,845), and by as much as 12 per cent for age-16 personality (from 3,751 to 4,205).

For each of the 22 items $i$, we estimate the following model to predict missing values:

$$
\text { Item }_{i}=\alpha+\sum_{j \neq i} \beta_{j} \text { Item }_{j}+\varepsilon
$$




\section{Figure A 1. Clustering of Age-16 Personality Items into Four Big Five Traits}

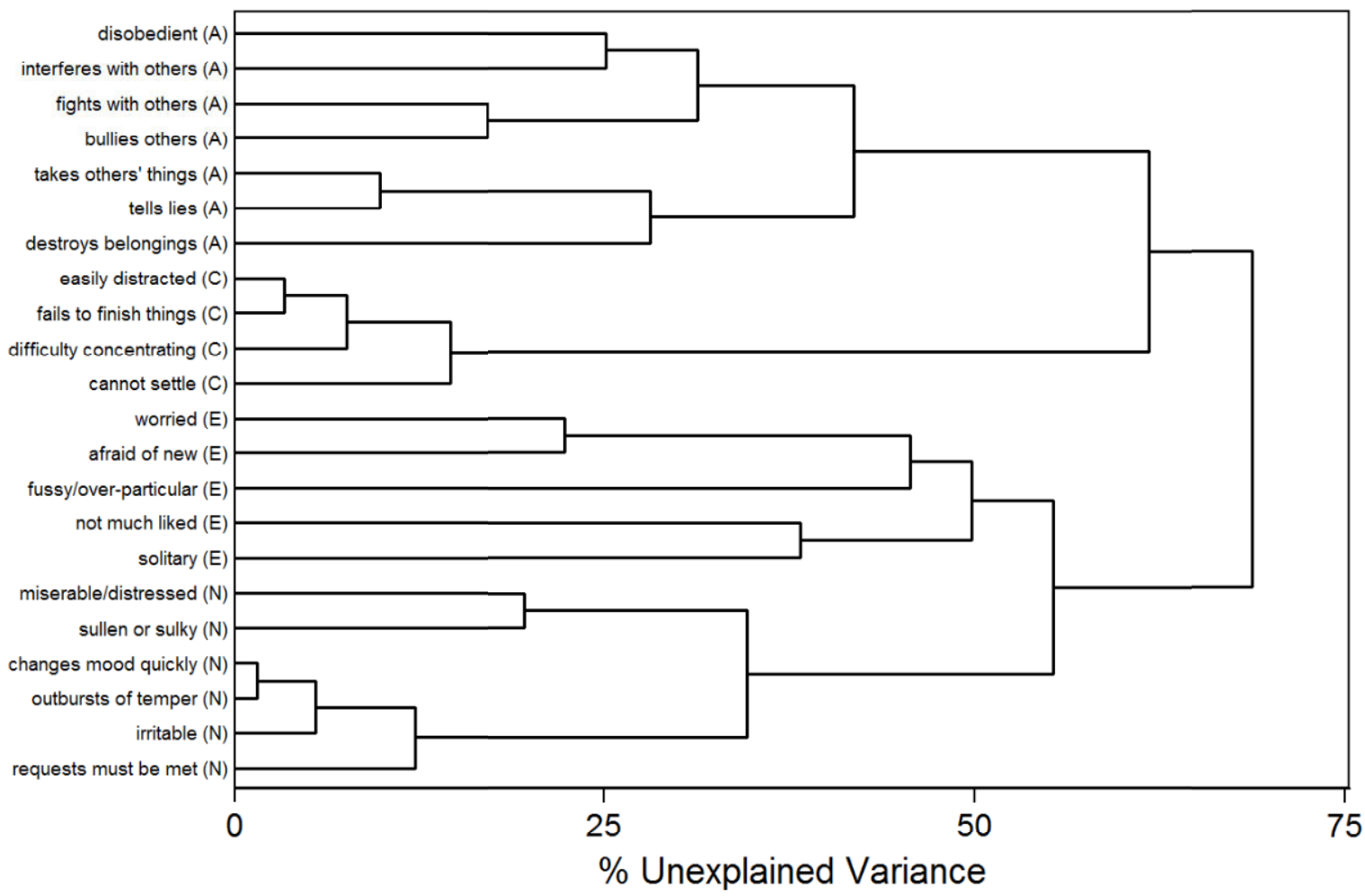

\begin{tabular}{|c|c|c|c|c|c|}
\hline & C & $\bar{E}$ & $\mathbf{A}$ & $\mathbf{N}$ & Unexplained \\
\hline fails to finish things (C) & .513 & & & & .274 \\
\hline easily distracted (C) & .468 & & & & .357 \\
\hline difficulty concentrating (C) & .496 & & & & .362 \\
\hline cannot settle $(\mathrm{C})$ & .410 & & & & .433 \\
\hline fussy/over-particular (E) & & .292 & & & .702 \\
\hline solitary (E) & & .417 & & & .644 \\
\hline afraid of new (E) & & .522 & & & .479 \\
\hline worried (E) & & .548 & & & .415 \\
\hline not much liked (E) & & .248 & .327 & & .635 \\
\hline bullies others (A) & & & .394 & & .510 \\
\hline fights with others (A) & & & .378 & & .516 \\
\hline tells lies (A) & & & .337 & & .486 \\
\hline disobedient (A) & & & .200 & .212 & .484 \\
\hline takes others' things (A) & & & .435 & & .475 \\
\hline destroys belongings (A) & & & .435 & & .517 \\
\hline interferes with others (A) & & & & & .611 \\
\hline outbursts of temper $(\mathrm{N})$ & & & & .419 & .341 \\
\hline changes mood quickly $(\mathrm{N})$ & & & & .430 & .319 \\
\hline irritable $(\mathrm{N})$ & & & & .412 & .395 \\
\hline requests must be met $(\mathrm{N})$ & & & & .368 & .444 \\
\hline sullen or sulky $(\mathrm{N})$ & & & & .355 & .514 \\
\hline miserable/distressed $(\mathrm{N})$ & & .244 & & .221 & .575 \\
\hline
\end{tabular}


This process starts with the item with least amount of missing observations. Missing observations are then imputed, and the process continues to the item with next fewest missing observations. At age 10, the items are scored on a scale from 1 through 100, 1 indicating "certainly" and 100 indicating "does not apply". We thus apply the above model using linear regression. Imputed values below 1 are set to 1 , and those above 100 are set to 100 . For the age-16 items we use multinomial logit regression to impute missing values, since the items are scored 1 "certainly applies, 2 "applies somewhat", 3 "doesn't apply".

Figure A1 shows a dendrogram of the clustering of the 22 items measured at age 16 (including imputed values). The grouping of items is as expected and is also confirmed by the table below. After extracting four factors from the same set of 22 items using principal component analysis, and applying orthogonal rotation to the loadings, the table below shows the factor loadings and the unexplained variance of the 22 items used to construct our four personality measures (conscientiousness, extraversion, agreeableness, and emotional stability). Only loadings larger than .2 are reported. The resulting four factors explain 52.3 per cent of the variance among the items.

\section{A2 Rutter, Self-esteem, and Locus of control}

In Section 4 we apply a number of other personality measures to control for early sociability. These measures include Rutter scores at various ages, indicative of behavioural problems, and measures for self-esteem and locus of control, measuring respondents' sense of self-worth and believe in the importance of trying hard.

At ages 5, 10, and 16, the respondents' parents, usually the mother, are asked to indicate to what extent a certain description applies to the respondent. At ages 5 and 16, the items are scaled 0 "does not apply" 1 "applies somewhat" 2 "certainly applies". The age-10 items are scaled 1 through 100 , where 1 indicates "does not apply" and 100 indicates "certainly applies". Higher scores indicate more severe behavioural problems.

The table below shows the inter-item correlations or covariances for the 16 items, and the Cronbach's alpha statistic for the scale formed from them. The three Rutter scores, at ages 5, 10, and 16, are constructed by summing the scores on the 16 mother-rated items, and then standardising the resulting score to have mean zero and standard deviation one.

Self-esteem assesses respondents' self-esteem with reference to teachers, peers and parents and consists of 12 items, while locus of control measures children's perceived achievement control with a list of 15 items. Items are scaled 0 "yes" 1 "don't know" 2 "no", except the first self-esteem item "Parent like to hear about ideas" and the locus of control item "Believe in planning ahead", which are reversely coded. Higher scores thus indicate higher self-esteem and higher internal locus of control. The table below shows the inter-item correlations or covariances for these sets of items, and the Cronbach's alpha statistic for the scale formed from them, both for ages 10 and 16 . The self-esteem and locus of control scores are constructed by summing the scores on the set of 12/15 items, and then standardising the resulting score to have mean zero and standard deviation one.

The samples used to construct Rutter scores, self-esteem and locus of control measures include respondents with valid observations on all items, as well as individuals with missing values for 1 or 2 items within each set of items (i.e. with only 13 of 15 age-16 locus of control items). The missing values have been imputed for these individuals. We apply multiple imputations through chained equations using the remaining items as predictors for the item of interest. By doing so, we increase the number of observations with valid observations drastically. For the Rutter scores, as well as for the self-esteem and locus of control measures, the resulting alphas are almost identical, whether or not we make use of imputed values, so to retain a large a sample as possible, we use the set of items that include imputed values to construct Rutter scores, as well as measures for self-esteem and locus of control. 


\begin{tabular}{|c|c|c|c|c|c|c|c|c|c|c|c|c|}
\hline & \multicolumn{4}{|c|}{ Age $5(n=12,965)$} & \multicolumn{4}{|c|}{ Age $10(n=13,337)$} & \multicolumn{4}{|c|}{ Age $16(n=8,609)$} \\
\hline & 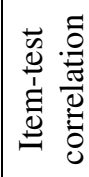 & 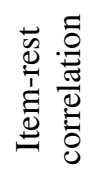 & 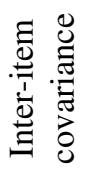 & $\frac{\frac{\pi}{2}}{\frac{2}{2}}$ & 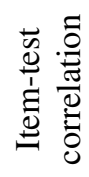 & 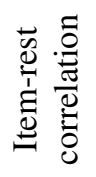 & 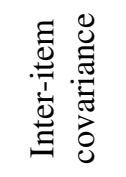 & $\frac{\pi}{\frac{\pi}{2}}$ & 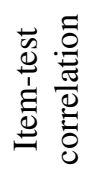 & 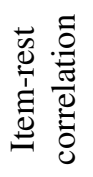 & 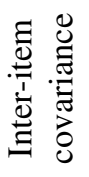 & $\frac{\widetilde{\sigma}}{\frac{0}{2}}$ \\
\hline Rutter & & & .06 & .76 & & & 124.17 & .80 & & & .05 & .80 \\
\hline restless & .57 & .43 & .05 & .74 & .54 & .41 & 119.58 & .80 & .48 & .38 & .05 & .79 \\
\hline squirmy/fidgety & .55 & .42 & .05 & .74 & .57 & .46 & 118.53 & .79 & .50 & .40 & .05 & .79 \\
\hline destroys belongings & .50 & .40 & .06 & .74 & .51 & .45 & 128.94 & .79 & .46 & .40 & .05 & .79 \\
\hline fights with others & .51 & .41 & .05 & .74 & .54 & .46 & 124.75 & .79 & .53 & .45 & .05 & .79 \\
\hline not much liked by others & .32 & .25 & .06 & .75 & .46 & .38 & 129.16 & .80 & .42 & .35 & .05 & .80 \\
\hline worried & .38 & .26 & .06 & .75 & .50 & .38 & 121.94 & .80 & .52 & .39 & .05 & .79 \\
\hline solitary, does things on own & .37 & .23 & .06 & .76 & .42 & .28 & 126.97 & .80 & .46 & .31 & .05 & .80 \\
\hline irritable & .58 & .47 & .05 & .73 & .61 & .51 & 115.65 & .79 & .66 & .54 & .04 & .78 \\
\hline miserable, tearful, distressed & .47 & .37 & .06 & .74 & .56 & .48 & 124.68 & .79 & .56 & .48 & .05 & .79 \\
\hline takes others' things & .42 & .32 & .06 & .75 & .48 & .42 & 129.97 & .80 & .48 & .41 & .05 & .79 \\
\hline disobedient & .60 & .50 & .05 & .73 & .62 & .53 & 118.20 & .79 & .64 & .54 & .04 & .78 \\
\hline cannot settle & .55 & .44 & .05 & .74 & .57 & .47 & 120.09 & .79 & .58 & .49 & .05 & .78 \\
\hline $\begin{array}{l}\text { afraid of new } \\
\text { things/situations }\end{array}$ & .33 & .19 & .06 & .76 & .42 & .29 & 127.36 & .80 & .45 & .33 & .05 & .80 \\
\hline fussy or over-particular & .37 & .22 & .06 & .76 & .40 & .27 & 127.90 & .80 & .42 & .28 & .05 & .80 \\
\hline tells lies & .49 & .40 & .06 & .74 & .56 & .48 & 123.85 & .79 & .56 & .48 & .05 & .79 \\
\hline bullies others & .46 & .38 & .06 & .75 & .52 & .46 & 129.13 & .79 & .48 & .42 & .05 & .79 \\
\hline
\end{tabular}

Note: Sample includes all respondents with valid information on the individual items, as well as imputed values for respondents with 1 or 2 missing values in the set of 16 rutter items. Values are imputed using multiple imputation through chained equations using the remaining items as regressors. Age 5 and 16 items are scaled 0 "does not apply" 1 "applies somewhat" 2 "certainly applies". Age 10 items are scaled 1 through 100 , where 1 indicates "does not apply" and 100 indicates "certainly applies". Higher scores thus indicate more severe behavioural problems.

Similar to the imputation applied for personality items, for each item $i$ within each set of Rutter/selfesteem/locus of control items, we estimate the following model to predict missing values:

$$
\text { Item }_{i}=\alpha+\sum_{j \neq i} \beta_{j} \text { Item }_{j}+\varepsilon
$$

This process starts with the item with least amount of missing observations. Missing observations are then imputed, and the process continues to the item with next fewest missing observations. For the age-10 Rutter score we apply the above model using linear regression, since the items are scaled from 1 through 100. Imputed values below 1 are set to 1 , and those above 100 are set to 100 . For the age-5 and age-16 Rutter scores, and the age-10 and age-16 self-esteem and locus of control scores, we use multinomial logit regression to impute missing values.

\begin{tabular}{|c|c|c|c|c|c|c|c|c|}
\hline & \multicolumn{4}{|c|}{$\begin{array}{l}\text { Age } 10(n=12,624 \text { for self- } \\
\text { esteem and } 12,560 \text { for } \\
\text { locus of control) }\end{array}$} & \multicolumn{4}{|c|}{$\begin{array}{l}\text { Age } 16(n=4,439 \text { for self- } \\
\text { esteem and } 5,479 \text { for } \\
\text { locus of control })\end{array}$} \\
\hline & 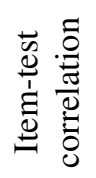 & 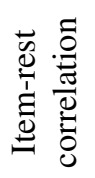 & 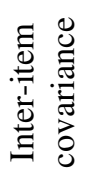 & $\frac{\pi}{\frac{\pi}{2}}$ & 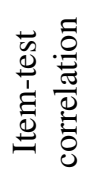 & 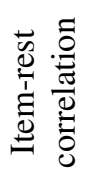 & 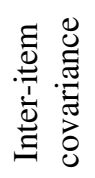 & $\frac{\frac{\pi}{2}}{\frac{2}{2}}$ \\
\hline Self-esteem & & & .10 & .69 & & & .09 & .70 \\
\hline 1. Parents like to hear about ideas & .26 & .12 & .11 & .69 & .38 & .23 & .09 & .70 \\
\hline 2. Feel lonely at school & .47 & .35 & .10 & .67 & .52 & .42 & .09 & .68 \\
\hline 3. Others fall out with you & .59 & .42 & .09 & .65 & .49 & .37 & .09 & .68 \\
\hline
\end{tabular}


4. Others say nasty things about you

5. Feel shy in front of teachers

6 . Feel sad because nobody to play/talk with

.09

7 . Like to change lots of things about self

8. Feel foolish talking to peers

9. Feel foolish talking to teacher

10. Often have to find new friends

11. Feel foolish talking to parents

12. Others think you tell lies

\section{Locus of control}

1. Not worth trying hard

2. Wishing makes good things happen

3. People good to you no matter what

4. Useless to try in school, others cleverer

5. High mark just a matter of luck

6. Tests just a lot of guess work

7. Blamed for things not your fault

8. Believe in planning ahead

9. Bad things someone else's fault

10. Someone angry, impossible to make friend again

11. Nice things only good luck

12. Arguments other person's fault

13. Surprised when teacher says done well

14. Low marks even when study hard

15. Studying for tests is waste of time

\begin{tabular}{llll|llll}
.55 & .40 & .09 & .65 & .57 & .43 & .08 & .67 \\
.45 & .27 & .10 & .68 & .59 & .42 & .08 & .67 \\
.55 & .40 & .09 & .65 & .48 & .32 & .09 & .69 \\
.49 & .31 & .10 & .67 & .48 & .30 & .09 & .69 \\
.7 & .31 & .10 & .67 & .52 & .32 & .08 & .69 \\
.44 & .31 & .10 & .67 & .58 & .44 & .08 & .67 \\
.56 & .39 & .09 & .66 & .53 & .33 & .09 & .69 \\
.28 & .20 & .11 & .68 & .33 & .23 & .10 & .70 \\
.52 & .39 & .10 & .66 & .43 & .29 & .09 & .69 \\
\hline & & .06 & .63 & & & .08 & .71 \\
.8 & .35 & .06 & .60 & .53 & .42 & .08 & .68 \\
.29 & .12 & .07 & .63 & .30 & .15 & .09 & .71 \\
.18 & .02 & .07 & .65 & .29 & .14 & .09 & .71 \\
.50 & .39 & .06 & .59 & .52 & .43 & .08 & .68 \\
.57 & .42 & .05 & .58 & .61 & .50 & .07 & .67 \\
.47 & .34 & .06 & .60 & .58 & .48 & .07 & .67 \\
.43 & .25 & .06 & .61 & .45 & .28 & .08 & .70 \\
.19 & .01 & .07 & .65 & .36 & .20 & .08 & .71 \\
.38 & .22 & .06 & .62 & .39 & .25 & .08 & .70 \\
.40 & .23 & .06 & .62 & .32 & .19 & .09 & .71 \\
.55 & .40 & .06 & .59 & .50 & .38 & .08 & .68 \\
.26 & .11 & .07 & .63 & .29 & .15 & .09 & .71 \\
.47 & .32 & .06 & .60 & .51 & .36 & .08 & .69 \\
.54 & .41 & .06 & .59 & .59 & .47 & .07 & .67 \\
.32 & .22 & .07 & .62 & .48 & .37 & .08 & .69 \\
\hline
\end{tabular}

Note: Sample includes all individuals with valid information on the individual items, as well as imputed values for individuals with 1 or 2 missing values in the set of self-esteem or locus of control items. Values are imputed using multiple imputation through chained equations using the remaining items as regressors. Items are scaled 0 "yes" 1 "don't know" 2 "no", except the first self-esteem item "Parent like to hear about ideas" and locus of control item "Believe in planning ahead", which are reversely coded. Higher scores thus indicate higher selfesteem and higher internal locus of control.

Table A 1. Description of Variables

\begin{tabular}{|c|c|}
\hline Variable & Description \\
\hline \multicolumn{2}{|c|}{ Socio-economic Outcomes } \\
\hline Gross hourly wage (34) & $\begin{array}{l}\text { Gross pay per week divided by usual hours worked per week. Gross pay per week } \\
\text { constructed using reported gross pay and reporting period (one week, two weeks, } \\
\text { four weeks, one calendar month, one year). Respondent excluded if reported weekly } \\
\text { hours is below } 5 \text { or exceeds } 80 \text {, and if pay per week is below } 32.5 \text { pounds (1\%) or } \\
\text { above } 3073 \text { pounds }(1 \%) \text {. }\end{array}$ \\
\hline $\begin{array}{l}\text { Log gross hourly wage } \\
\text { (34) }\end{array}$ & Log of Gross hourly wage (34) \\
\hline Save & "Do you save any amount of your income?". Dummy variable. 0 "No" 1 "Yes". \\
\hline BMI (Body Mass Index) & Standard Body Mass Index (Weight in kilos/(Length in meters^2)). \\
\hline Alcoholic (CAGE $>=2)$ & $\begin{array}{l}\text { Dummy variable equal to one if respondent answered yes to two, three or all four } \\
\text { questions from the CAGE (Cutting down, Annoyance by criticism, Guilty feeling and } \\
\text { Eye-openers) questionnaire. Equal to zero is answered zero or one of the questions } \\
\text { with yes. It indicates potential alcohol dependence or abuse. }\end{array}$ \\
\hline Smoke & $\begin{array}{l}\text { Dummy variable equal to one if respondent smokes (from occasionally to more than } \\
20 \text { cigarettes daily). Equal to zero if respondent has never smoked or is an ex-smoker. }\end{array}$ \\
\hline (Use) Cannabis & $\begin{array}{l}\text { Dummy variable equal to one if respondent uses cannabis (from occasionally to on } \\
\text { most days). Equal to zero if respondent never tried cannabis or never uses cannabis } \\
\text { nowadays. }\end{array}$ \\
\hline (Ever) Arrested & $\begin{array}{l}\text { "Have you been arrested by a police officer and taken to a police station? (Type in } \\
\text { number of times)" Dummy variable. } 0 \text { " } 0 " 1 \text { " } 1-9 " \text {. }\end{array}$ \\
\hline $\begin{array}{l}\text { Satisfaction } \\
\text { (with life }(0-10))\end{array}$ & $\begin{array}{l}\text { "How satisfied or dissatisfied are you with the way life has turned out so far?" Scaled } \\
0 \text { through } 10.0 \text { "Completely dissatisfied" to } 10 \text { "Completely satisfied". }\end{array}$ \\
\hline
\end{tabular}




\begin{tabular}{|c|c|}
\hline Variable & Description \\
\hline $\begin{array}{l}\text { Life Get (I get what I } \\
\text { want out of life) }\end{array}$ & $\begin{array}{l}\text { Dummy variable. "Which of these two statements is more true for you?" } 0 \text { "I never } \\
\text { really seem to get what I want out of life." } 1 \text { "I usually get what I want out of life." }\end{array}$ \\
\hline $\begin{array}{l}\text { Life Run (I can run life as } \\
\text { I want) }\end{array}$ & $\begin{array}{l}\text { Dummy variable. "Which of these two statements is more true for you?" } 0 \text { "I usually } \\
\text { find life's problems just too much for me." } 1 \text { "Usually I can run my life more or less } \\
\text { as I want to." }\end{array}$ \\
\hline \multicolumn{2}{|l|}{ Personality } \\
\hline Conscientiousness (10) & $\begin{array}{l}\text { Standardized Principal Component of } 4 \text { age-10 items related to Conscientiousness. } \\
\text { See Table } 1 \text { and Appendix for details. }\end{array}$ \\
\hline Extraversion (10) & $\begin{array}{l}\text { Standardized Principal Component of } 5 \text { age-10 items related to Extraversion. See } \\
\text { Table } 1 \text { and Appendix for details. }\end{array}$ \\
\hline Agreeableness (10) & $\begin{array}{l}\text { Standardized Principal Component of } 7 \text { age-10 items related to Agreeableness. See } \\
\text { Table } 1 \text { and Appendix for details. }\end{array}$ \\
\hline Emotional Stability (10) & $\begin{array}{l}\text { Standardized Principal Component of } 6 \text { age-10 items related to Emotional Stability. } \\
\text { See Table } 1 \text { and Appendix for details. }\end{array}$ \\
\hline Conscientiousness (16) & $\begin{array}{l}\text { Standardized Principal Component of } 4 \text { age-16 items related to Conscientiousness. } \\
\text { See Table } 1 \text { and Appendix for details. }\end{array}$ \\
\hline Extraversion (16) & $\begin{array}{l}\text { Standardized Principal Component of } 5 \text { age-16 items related to Extraversion. See } \\
\text { Table } 1 \text { and Appendix for details. }\end{array}$ \\
\hline Agreeableness (16) & $\begin{array}{l}\text { Standardized Principal Component of } 7 \text { age-16 items related to Agreeableness. See } \\
\text { Table } 1 \text { and Appendix for details. }\end{array}$ \\
\hline Emotional Stability (16) & $\begin{array}{l}\text { Standardized Principal Component of } 6 \text { age-16 items related to Emotional Stability. } \\
\text { See Table } 1 \text { and Appendix for details. }\end{array}$ \\
\hline \multicolumn{2}{|l|}{ Home Environment } \\
\hline No dad at birth & $\begin{array}{l}\text { Dummy variable equal to one if father absent in household at birth of respondent, } \\
\text { zero if father present. }\end{array}$ \\
\hline Mom teenage mother & $\begin{array}{l}\text { Dummy variable equal to one if mother's age at first birth was below } 20 \text {, and zero if } \\
\text { age at first birth was } 20 \text { or higher. }\end{array}$ \\
\hline Yrs of schooling mom & her left full-time education minus six \\
\hline Yrs of schooling dad & r left full-time ed \\
\hline Parent skilled/prof. (0) & $\begin{array}{l}\text { Social class at birth: fathers occupation (or mothers if missing). Dummy variable. } 0 \text { if } \\
\text { student, unskilled, or partly skilled. } 1 \text { if skilled (non-)manual, managerial/technical, } \\
\text { or professional. }\end{array}$ \\
\hline Liberal worldview (5) & $\begin{array}{l}\text { Principal component of } 5 \text { mother-rated items at age } 5 \text {. Higher score indicates more } \\
\text { liberal views. }\end{array}$ \\
\hline Child to be left free (5) & $\begin{array}{l}\text { Principal component of } 13 \text { mother-rated items at age } 5 \text {. Higher score indicates } \\
\text { disagreement with authoritarian childrearing. }\end{array}$ \\
\hline Child to be controlled (5) & $\begin{array}{l}\text { Principal component of } 7 \text { mother-rated items at age } 5 \text {. Higher score indicates } \\
\text { disagreement with the opinion that children should be allowed to be themselves. }\end{array}$ \\
\hline Strong family ties (10) & $\begin{array}{l}\text { Average score on } 7 \text { family activities (go for walks, outings, holidays, go shopping, go } \\
\text { to restaurants, have meals, have talks together), each scaled } 1 \text { "rarely/never" } 2 \\
\text { "sometimes" } 3 \text { "often" (Cronbach's alpha 0.66) }\end{array}$ \\
\hline $\begin{array}{l}\text { Don't get on with parents } \\
\text { (16) }\end{array}$ & $\begin{array}{l}\text { Average score on } 11 \text { self-rated items about how parents treat respondent } \\
\text { (overprotective, treat me like a child, don't understand me, are strict/bossy), each } \\
\text { scaled } 0 \text { "no" } 1 \text { "yes" (Cronbach's alpha } 0.73 \text { ) }\end{array}$ \\
\hline $\begin{array}{l}\text { Parents are free, not strict } \\
(16)\end{array}$ & $\begin{array}{l}\text { "Some parents are very strict, and others give lots of freedom. What about yours?" } \\
\text { Scaled } 1 \text { "very strict through } 7 \text { "very free". }\end{array}$ \\
\hline \multicolumn{2}{|c|}{ Educational Achievement } \\
\hline Cognitive Ability & $\begin{array}{l}\text { We construct a measure using test scores at age } 10 \text { because cognitive ability seems to } \\
\text { be set at that age (e.g., Lebel and Beaulieu, 2011). Cognitive ability is measured by } \\
\text { extracting the first principal component from a set of } 8 \text { standardized test scores, all } \\
\text { measured at the age of } 10 \text {. The resulting score is standardized to have zero mean and } \\
\text { a standard deviation of one. The test scores include the four British Ability Scales } \\
\text { (word definitions, recall of digits, similarities, matrices), as well as the Shortened } \\
\text { Edinburgh Reading Test, the CHES Pictorial Language Comprehension and Friendly } \\
\text { Maths tests, and a spelling test. Cronbach's alpha on the set of test scores is } 0.89 \text { and } \\
\text { the explained variance of the resulting principal component is } 58 \text { per cent. }\end{array}$ \\
\hline Years of schooling (34) & Age left full-time education minus six \\
\hline Skilled/prof. (34) & Social class at age 34 , from occupation. Dummy variable. 0 if unskilled, or $\mathrm{p}$ \\
\hline
\end{tabular}




\begin{tabular}{|c|c|}
\hline Variable & Description \\
\hline & skilled. 1 if skilled (non-)manual, managerial/technical, or professional. \\
\hline \multicolumn{2}{|l|}{ Sociability } \\
\hline Rutter score (5) & $\begin{array}{l}\text { Standardized sum of scores on } 16 \text { mother-rated age- } 5 \text { items on behaviour problems } \\
\text { (mean } 0 \text {, st.dev. 1). Missing values are imputed for respondents with } 1 \text { or } 2 \text { missings } \\
\text { out of } 16 \text { items. See Appendix for details on items. }\end{array}$ \\
\hline Rutter score (10) & $\begin{array}{l}\text { Standardized sum of scores on } 16 \text { mother-rated age- } 10 \text { items on behaviour problems } \\
\text { (mean } 0 \text {, st.dev. 1). Missing values are imputed for respondents with } 1 \text { or } 2 \text { missings } \\
\text { out of } 16 \text { items. See Appendix for details on items. }\end{array}$ \\
\hline Rutter score (16) & $\begin{array}{l}\text { Standardized sum of scores on } 16 \text { mother-rated age- } 16 \text { items on behaviour problems } \\
\text { (mean } 0 \text {, st.dev. 1). Missing values are imputed for respondents with } 1 \text { or } 2 \text { missings } \\
\text { out of } 16 \text { items. See Appendix for details on items. }\end{array}$ \\
\hline Self-esteem (10) & $\begin{array}{l}\text { Standardized sum of scores on } 12 \text { self-rated age } 10 \text { self-esteem items (mean } 0 \text {, st.dev. } \\
\text { 1). Missing values are imputed for respondents with } 1 \text { or } 2 \text { missings out of } 12 \text { items. } \\
\text { See Appendix for details on items. }\end{array}$ \\
\hline Locus of control (10) & $\begin{array}{l}\text { Standardized sum of scores on } 15 \text { self-rated age } 10 \text { locus of control items (mean } 0 \text {, } \\
\text { st.dev. 1). Missing values are imputed for respondents with } 1 \text { or } 2 \text { missings out of } 15 \\
\text { items. See Appendix for details on items. }\end{array}$ \\
\hline Self-esteem (16) & $\begin{array}{l}\text { Standardized sum of scores on } 12 \text { self-rated age } 16 \text { self-esteem items (mean } 0 \text {, st.dev. } \\
\text { 1). Missing values are imputed for respondents with } 1 \text { or } 2 \text { missings out of } 12 \text { items. } \\
\text { See Appendix for details on items. }\end{array}$ \\
\hline Locus of control (16) & $\begin{array}{l}\text { Standardized sum of scores on } 15 \text { self-rated age } 16 \text { locus of control items (mean } 0 \text {, } \\
\text { st.dev. 1). Missing values are imputed for respondents with } 1 \text { or } 2 \text { missings out of } 15 \\
\text { items. See Appendix for details on items. }\end{array}$ \\
\hline Sports in school & $\begin{array}{l}\text { "During the past year, which of the following sports did you play when they were in } \\
\text { season?" Count of sports indicated to have played in school in the past year }\end{array}$ \\
\hline Sports outside school & $\begin{array}{l}\text { "During the past year, which of the following sports did you play when they were in } \\
\text { season?" Count of sports indicated to have played out of school in the past year }\end{array}$ \\
\hline No. friends in school & $\begin{array}{l}\text { "How many other close friends have you got at your school or outside?" Ranging } \\
\text { from } 0 \text { " } 0 \text { " to } 9 \text { "9 or more". }\end{array}$ \\
\hline $\begin{array}{l}\text { No. friends outside } \\
\text { school }\end{array}$ & $\begin{array}{l}\text { "How many other close friends have you got at your school or outside?" Ranging } \\
\text { from } 0 \text { "0" to } 9 \text { "9 or more". }\end{array}$ \\
\hline \multicolumn{2}{|l|}{ Occupational Sorting } \\
\hline $\begin{array}{l}\text { Avg Occ. } \\
\text { Conscientiousness (16) }\end{array}$ & $\begin{array}{l}\text { Average score on age } 16 \text { conscientiousness, by age } 34 \text { occupation. See Table A5 for } \\
\text { list of occupations and averages. }\end{array}$ \\
\hline $\begin{array}{l}\text { Avg Occ. } \\
\text { Extraversion (16) }\end{array}$ & $\begin{array}{l}\text { Average score on age } 16 \text { extraversion, by age } 34 \text { occupation. See Table A5 for list of } \\
\text { occupations and averages. }\end{array}$ \\
\hline $\begin{array}{l}\text { Avg Occ. } \\
\text { Agreeableness (16) }\end{array}$ & $\begin{array}{l}\text { Average score on age } 16 \text { agreeableness, by age } 34 \text { occupation. See Table A5 for list } \\
\text { of occupations and averages. }\end{array}$ \\
\hline $\begin{array}{l}\text { Avg Occ. } \\
\text { Emotional Stability (16) }\end{array}$ & $\begin{array}{l}\text { Average score on age } 16 \text { emotional stability, by age } 34 \text { occupation. See Table A5 for } \\
\text { list of occupations and averages. }\end{array}$ \\
\hline $\begin{array}{l}\text { Above Avg Occ. } \\
\text { Conscientiousness (16) }\end{array}$ & $\begin{array}{l}\text { Dummy equal to } 1 \text { if respondents age- } 16 \text { conscientiousness is larger than the average } \\
\text { age- } 16 \text { conscientiousness of men in the same age } 34 \text { occupation }\end{array}$ \\
\hline $\begin{array}{l}\text { Above Avg Occ. } \\
\text { Extraversion (16) }\end{array}$ & $\begin{array}{l}\text { Dummy equal to } 1 \text { if respondents age- } 16 \text { extraversion is larger than the average age- } \\
16 \text { extraversion of men in the same age } 34 \text { occupation }\end{array}$ \\
\hline $\begin{array}{l}\text { Above Avg Occ. } \\
\text { Agreeableness (16) }\end{array}$ & $\begin{array}{l}\text { Dummy equal to } 1 \text { if respondents age-16 agreeableness is larger than the average } \\
\text { age- } 16 \text { agreeableness of men in the same age } 34 \text { occupation }\end{array}$ \\
\hline $\begin{array}{l}\text { Above Avg Occ. } \\
\text { Emotional Stability (16) }\end{array}$ & $\begin{array}{l}\text { Dummy equal to } 1 \text { if respondents age- } 16 \text { emotional stability is larger than the average } \\
\text { age- } 16 \text { emotional stability of men in the same age } 34 \text { occupation }\end{array}$ \\
\hline Social class dummies & $\begin{array}{l}\text { Social class at age } 34, \text { from occupation. } 6 \text { categories: professional, } \\
\text { managerial/technical, skilled non-manual, skilled manual, partly skilled, unskilled }\end{array}$ \\
\hline Years in current job & $\begin{array}{l}\text { Constructed using year and month of interview alongside year and month started } \\
\text { current main job }\end{array}$ \\
\hline
\end{tabular}


Table A 2. Descriptive Statistics (Working Sample and Unrestricted Sample)

\begin{tabular}{|c|c|c|c|c|c|c|c|c|c|}
\hline & \multicolumn{6}{|c|}{ "Working Sample } & \multicolumn{3}{|c|}{ Unrestricted Sample } \\
\hline & $\min$ & $\max$ & count & mean & sd & median & count & mean & sd \\
\hline \multicolumn{10}{|l|}{ Socio-economic outcomes } \\
\hline $\begin{array}{l}\text { Log gross hourly wage } \\
\text { (34) }\end{array}$ & -0.59 & 4.72 & 2,934 & 2.41 & 0.54 & 2.41 & 6,106 & 2.40 & 0.54 \\
\hline Gross hourly wage (34) & 0.55 & 112.18 & 2,934 & 12.95 & 8.23 & 11.17 & 6,106 & 12.83 & 8.14 \\
\hline Save & 0.00 & 1.00 & 2,933 & 0.70 & 0.46 & 1.00 & 9,630 & $0.62 *$ & 0.49 \\
\hline BMI (Body Mass Index) & 9.58 & 66.56 & 2,864 & 25.92 & 4.76 & 25.17 & 9,355 & 25.89 & 4.93 \\
\hline Smoke & 0.00 & 1.00 & 2,933 & 0.26 & 0.44 & 0.00 & 9,634 & $0.31 *$ & 0.46 \\
\hline Alcoholic (CAGE >=2) & 0.00 & 1.00 & 2,902 & 0.18 & 0.39 & 0.00 & 9,386 & 0.18 & 0.39 \\
\hline (Use) Cannabis & 0.00 & 1.00 & 2,932 & 0.15 & 0.35 & 0.00 & 9,598 & $0.16^{*}$ & 0.37 \\
\hline (Ever) Arrested & 0.00 & 1.00 & 2,932 & 0.14 & 0.35 & 0.00 & 10,182 & $0.21 *$ & 0.41 \\
\hline $\begin{array}{l}\text { Satisfaction } \\
\text { (with life }(0-10))\end{array}$ & 0.00 & 10.00 & 2,932 & 7.50 & 1.61 & 8.00 & 9,594 & $7.40 *$ & 1.80 \\
\hline $\begin{array}{l}\text { Life Get } \\
\text { (I get what I want out of } \\
\text { life) }\end{array}$ & 0.00 & 1.00 & 2,932 & 0.84 & 0.36 & 1.00 & 9,577 & $0.82 *$ & 0.38 \\
\hline $\begin{array}{l}\text { Life Run } \\
\text { (I can run life as I want) }\end{array}$ & 0.00 & 1.00 & 2,932 & 0.97 & 0.18 & 1.00 & 9,587 & $0.95 *$ & 0.22 \\
\hline \multicolumn{10}{|l|}{ Personality } \\
\hline Conscientiousness (10) & -3.08 & 1.21 & 2,796 & 0.12 & 0.92 & 0.42 & 13,392 & $0.00 *$ & 1.00 \\
\hline Extraversion (10) & -4.25 & 1.60 & 2,786 & 0.04 & 0.98 & 0.25 & 13,353 & $0.00 *$ & 1.00 \\
\hline Agreeableness (10) & -5.23 & 1.32 & 2,787 & 0.14 & 0.83 & 0.23 & 13,337 & $0.00 *$ & 1.00 \\
\hline Emotional Stability (10) & -3.70 & 1.33 & 2,790 & 0.13 & 0.90 & 0.36 & 13,352 & $0.00 *$ & 1.00 \\
\hline Conscientiousness (16) & -4.54 & 0.73 & 2,934 & 0.12 & 0.89 & 0.34 & 8,634 & $0.00 *$ & 1.00 \\
\hline Extraversion (16) & -5.31 & 0.99 & 2,934 & 0.06 & 0.94 & 0.32 & 8,613 & $0.00 *$ & 1.00 \\
\hline Agreeableness (16) & -6.63 & 0.54 & 2,934 & 0.13 & 0.78 & 0.54 & 8,600 & $0.00^{*}$ & 1.00 \\
\hline Emotional Stability (16) & -4.38 & 0.87 & 2,934 & 0.10 & 0.90 & 0.33 & 8,607 & $0.00^{*}$ & 1.00 \\
\hline \multicolumn{10}{|l|}{ Home Environment } \\
\hline No dad at birth & 0.00 & 1.00 & 2,932 & 0.02 & 0.15 & 0.00 & 17,099 & $0.05 *$ & 0.21 \\
\hline Mom teenmother & 0.00 & 1.00 & 2,919 & 0.15 & 0.36 & 0.00 & 17,078 & $0.20^{*}$ & 0.40 \\
\hline Yrs of schooling mom & 0.00 & 21.00 & 2,917 & 9.84 & 1.76 & 9.00 & 17,049 & $9.66^{*}$ & 1.83 \\
\hline Yrs of schooling dad & 0.00 & 32.00 & 2,845 & 10.08 & 2.36 & 9.00 & 16,213 & $9.92 *$ & 2.35 \\
\hline Parent skilled/prof. (0) & 0.00 & 1.00 & 2,934 & 0.82 & 0.39 & 1.00 & 17,175 & $0.76^{*}$ & 0.43 \\
\hline Liberal worldview (5) & -2.30 & 2.41 & 2,662 & 0.11 & 1.01 & 0.10 & 12,978 & $0.00^{*}$ & 1.00 \\
\hline Child to be left free (5) & -2.60 & 2.83 & 2,664 & 0.12 & 0.94 & 0.10 & 12,990 & $0.00 *$ & 1.00 \\
\hline Child to be controlled (5) & -2.15 & 3.41 & 2,664 & 1.03 & 0.97 & 1.05 & 12,988 & 1.00 & 1.00 \\
\hline Strong family ties (10) & 1.00 & 3.00 & 2,816 & 2.51 & 0.30 & 2.57 & 13,627 & $2.47^{*}$ & 0.32 \\
\hline $\begin{array}{l}\text { Don't get on with } \\
\text { parents }(16)\end{array}$ & -0.45 & 0.55 & 1,866 & -0.23 & 0.21 & -0.27 & 6,349 & $-0.21 *$ & 0.21 \\
\hline $\begin{array}{l}\text { Parents are free, not } \\
\operatorname{strict}(16)\end{array}$ & 1.00 & 7.00 & 1,856 & 4.53 & 1.18 & 5.00 & 6,268 & 4.56 & 1.26 \\
\hline \multicolumn{10}{|l|}{ Education } \\
\hline Cognitive ability & -2.97 & 2.86 & 2,934 & 0.28 & 0.91 & 0.33 & 11,116 & $0.00 *$ & 1.00 \\
\hline Years of schooling (34) & 8.00 & 28.00 & 2,933 & 12.86 & 3.81 & 11.00 & 9,632 & $12.67 *$ & 3.91 \\
\hline
\end{tabular}




\begin{tabular}{|c|c|c|c|c|c|c|c|c|c|}
\hline & \multicolumn{6}{|c|}{ Working Sample } & \multicolumn{3}{|c|}{ Unrestricted Sample } \\
\hline & $\min$ & $\max$ & count & mean & sd & median & count & mean & sd \\
\hline Skilled/prof. (34) & 0.00 & 1.00 & 2,933 & 0.59 & 0.49 & 1.00 & 9,632 & $0.54 *$ & 0.50 \\
\hline \multicolumn{10}{|l|}{ Sociability } \\
\hline Rutter score (5) & -1.69 & 4.80 & 2,662 & -0.10 & 0.94 & -0.18 & 12,965 & $0.00 *$ & 1.00 \\
\hline Rutter score (10) & -2.02 & 3.81 & 2,784 & -0.13 & 0.92 & -0.19 & 13,337 & $0.00 *$ & 1.00 \\
\hline Rutter score (16) & -1.08 & 7.95 & 2,930 & -0.12 & 0.86 & -0.37 & 8,609 & $0.00 *$ & 1.00 \\
\hline Self-esteem (10) & 2.00 & 24.00 & 2,909 & 16.78 & 4.45 & 17.00 & 12,624 & $16.39 *$ & 4.54 \\
\hline Locus of control (10) & 2.00 & 30.00 & 2,899 & 18.53 & 4.64 & 19.00 & 12,560 & $17.85^{*}$ & 4.75 \\
\hline Sports in school & 0.00 & 57.00 & 1,496 & 9.34 & 8.20 & 8.00 & 5,265 & 9.20 & 8.30 \\
\hline Sports outside school & 0.00 & 60.00 & 1,496 & 8.88 & 7.76 & 7.00 & 5,265 & 8.91 & 8.11 \\
\hline No. friends in school & 0.00 & 9.00 & 1,827 & 5.68 & 2.85 & 5.00 & 6,093 & 5.61 & 2.90 \\
\hline No. friends outside school & 0.00 & 9.00 & 1,792 & 4.83 & 3.21 & 4.00 & 5,967 & 4.90 & 3.19 \\
\hline \multicolumn{10}{|l|}{ Occupational Sorting } \\
\hline Avg Occ.Conscient.(16) & -0.30 & 0.53 & 2,929 & 0.09 & 0.21 & 0.12 & 7,989 & $0.07 *$ & 0.21 \\
\hline Avg Occ.Extrav.(16) & -0.27 & 0.38 & 2,929 & 0.05 & 0.10 & 0.05 & 7,989 & 0.05 & 0.11 \\
\hline Avg Occ.Agreeabl.(16) & -0.35 & 0.43 & 2,929 & 0.10 & 0.14 & 0.13 & 7,989 & $0.09^{*}$ & 0.15 \\
\hline Avg Occ.Emot.Stab.(16) & -0.15 & 0.40 & 2,929 & 0.09 & 0.12 & 0.12 & 7,989 & 0.09 & 0.12 \\
\hline Above Avg Occ. C (16) & 0.00 & 1.00 & 2,929 & 0.69 & 0.46 & 1.00 & 5,011 & 0.67 & 0.47 \\
\hline Above Avg Occ. E (16) & 0.00 & 1.00 & 2,929 & 0.57 & 0.50 & 1.00 & 4,993 & 0.57 & 0.50 \\
\hline Above Avg Occ. A (16) & 0.00 & 1.00 & 2,929 & 0.72 & 0.45 & 1.00 & 4,991 & 0.70 & 0.46 \\
\hline Above Avg Occ. N (16) & 0.00 & 1.00 & 2,929 & 0.62 & 0.49 & 1.00 & 4,994 & 0.61 & 0.49 \\
\hline
\end{tabular}

Note: Unrestricted sample gives count, mean, and standard deviation of each variable of interest. So the complete set of individuals for which that single variable is measured. The same information is stated for the working sample (as well as minimum and maximum). The working sample only contains the 2,934 individuals with valid data on age 34 gross hourly wages, age-10 cognitive ability, age-16 personality (conscientiousness, extraversion, agreeableness, and emotional stability), and region of birth. * Indicates unrestricted mean is significantly different from working mean at the 10 per cent level (2-sided t-test).

Table A 3. Means for Individuals Below and Above Average Wages and Personality

\begin{tabular}{|c|c|c|c|c|c|c|c|c|c|c|}
\hline \multirow[b]{2}{*}{ Socio-economic outcomes } & \multicolumn{2}{|c|}{\begin{tabular}{|c|} 
Gross hourly \\
wage \\
$\leq$ avg. $>$ avg.
\end{tabular}} & \multicolumn{2}{|c|}{$\begin{array}{l}\text { Conscientious- } \\
\text { ness } \\
\text { < avg. > avg. }\end{array}$} & \multicolumn{2}{|c|}{$\begin{array}{l}\text { Extraversion } \\
\leq \text { avg. > avg. }\end{array}$} & \multicolumn{2}{|c|}{$\begin{array}{l}\text { Agreeableness } \\
\leq \text { avg. > avg. }\end{array}$} & \multicolumn{2}{|c|}{\begin{tabular}{|c|} 
Emotional \\
Stability \\
$\leq$ avg. $>$ avg \\
\end{tabular}} \\
\hline & & & & & & & & & & \\
\hline Log gross hourly wage (34) & 2.09 & $2.93^{*}$ & 2.32 & $2.46^{*}$ & 2.38 & $2.44 *$ & 2.32 & $2.46^{*}$ & 2.35 & $2.45^{*}$ \\
\hline Gross hourly wage (34) & 8.55 & $19.93^{*}$ & 11.56 & $13.61 *$ & 12.56 & $13.28 *$ & 11.69 & $13.56^{*}$ & 12.22 & $13.39 *$ \\
\hline Save & 0.64 & $0.80 *$ & 0.63 & $0.73 *$ & 0.70 & 0.70 & 0.64 & $0.73 *$ & 0.65 & $0.73 *$ \\
\hline BMI (Body Mass Index) & 26.07 & $25.69 *$ & 26.50 & $25.64 *$ & 25.97 & 25.88 & 26.51 & $25.64 *$ & 26.21 & $25.75^{*}$ \\
\hline Smoke & 0.31 & $0.19 *$ & 0.36 & $0.22 *$ & 0.26 & 0.27 & 0.38 & $0.21 *$ & 0.31 & $0.24 *$ \\
\hline Alcoholic (CAGE $>=2$ ) & 0.16 & $0.22 *$ & 0.20 & $0.17 *$ & 0.17 & 0.19 & 0.19 & 0.18 & 0.18 & 0.18 \\
\hline (Use) Cannabis & 0.14 & 0.16 & 0.19 & $0.13^{*}$ & 0.14 & 0.15 & 0.19 & $0.13^{*}$ & 0.16 & 0.14 \\
\hline (Ever) Arrested & 0.16 & $0.13^{*}$ & 0.21 & $0.11^{*}$ & 0.13 & 0.15 & 0.22 & $0.11^{*}$ & 0.17 & $0.13^{*}$ \\
\hline $\begin{array}{l}\text { Satisfaction } \\
\text { (with life }(0-10) \text { ) }\end{array}$ & 7.34 & $7.74 *$ & 7.23 & $7.62^{*}$ & 7.32 & $7.65^{*}$ & 7.28 & $7.60^{*}$ & 7.38 & $7.57^{*}$ \\
\hline Life Get (I get what & 0.79 & $0.92 *$ & 0.78 & $0.87 *$ & 0.80 & $0.88 *$ & 0.78 & $0.87^{*}$ & 0.81 & $0.86^{*}$ \\
\hline
\end{tabular}




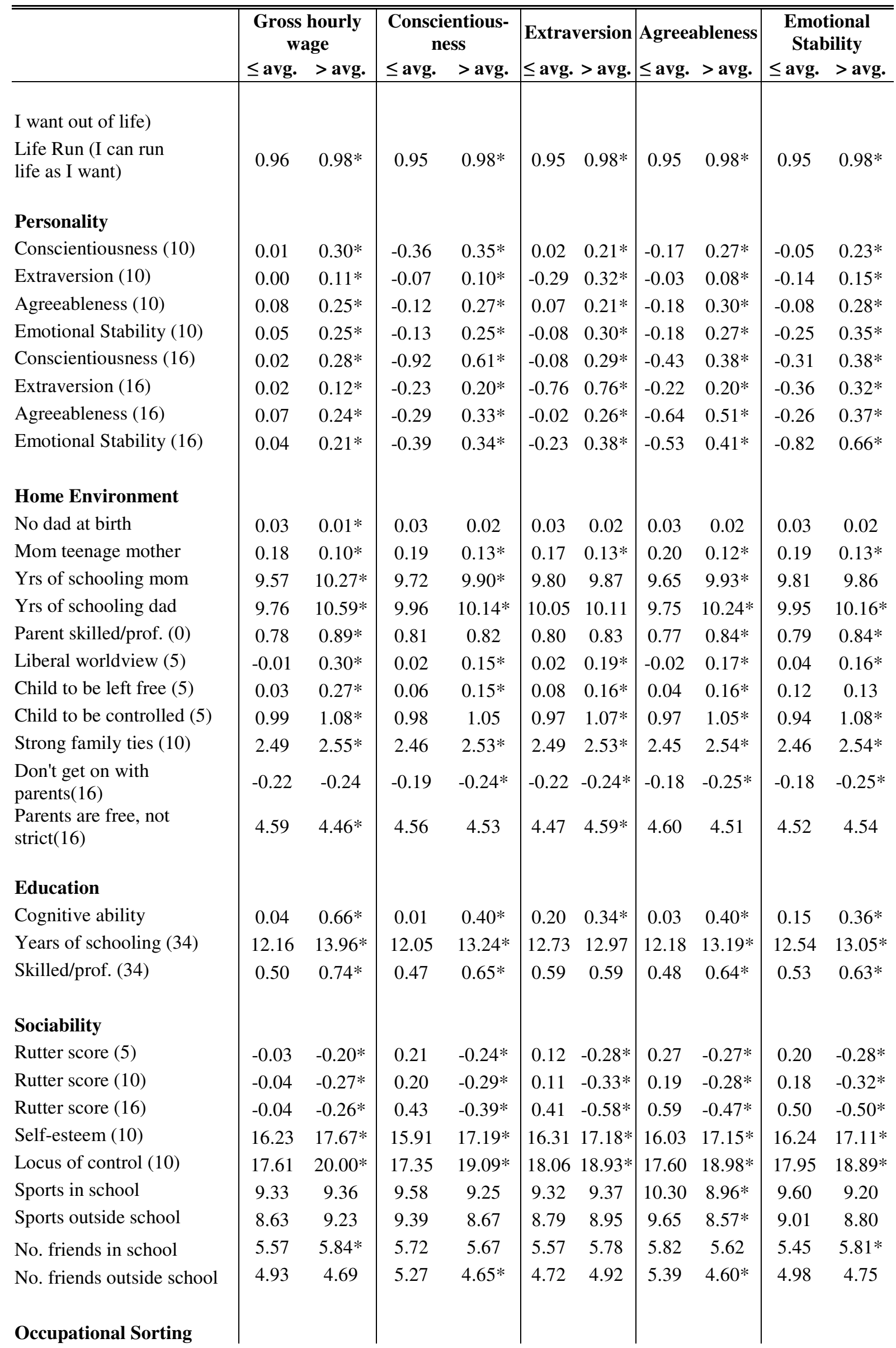




\begin{tabular}{|c|c|c|c|c|c|c|c|c|c|c|}
\hline & \multicolumn{2}{|c|}{$\begin{array}{l}\text { Gross hourly } \\
\text { wage }\end{array}$} & \multicolumn{2}{|c|}{$\begin{array}{c}\text { Conscientious- } \\
\text { ness }\end{array}$} & \multicolumn{2}{|c|}{ Extraversion } & \multicolumn{2}{|c|}{ Agreeableness } & \multicolumn{2}{|c|}{$\begin{array}{c}\text { Emotional } \\
\text { Stability }\end{array}$} \\
\hline & $\leq$ avg. & $>$ avg. & $\leq$ avg. & $>$ avg. & $\leq$ avg. & $>$ avg. & $\leq$ avg. & $>$ avg. & $\leq$ avg. & $>$ avg \\
\hline Avg Occ.Conscient.(16) & 0.02 & $0.20 *$ & 0.03 & $0.12 *$ & 0.09 & 0.09 & 0.04 & $0.12 *$ & 0.07 & $0.10 *$ \\
\hline Avg Occ.Extrav.(16) & 0.03 & $0.09 *$ & 0.05 & 0.05 & 0.04 & $0.06^{*}$ & 0.04 & $0.05^{*}$ & 0.04 & $0.05 *$ \\
\hline Avg Occ.Agreeabl.(16) & 0.06 & $0.17 *$ & 0.06 & $0.12 *$ & 0.10 & 0.10 & 0.06 & $0.12 *$ & 0.09 & $0.11 *$ \\
\hline Avg Occ.Emot.Stab.(16) & 0.05 & $0.16^{*}$ & 0.07 & $0.10^{*}$ & 0.09 & $0.09 *$ & 0.06 & $0.10 *$ & 0.07 & $0.10^{*}$ \\
\hline Above Avg Occ. C (16) & 0.66 & $0.73 *$ & 0.08 & $0.97^{*}$ & 0.59 & $0.76^{*}$ & 0.45 & $0.80 *$ & 0.50 & $0.80^{*}$ \\
\hline Above Avg Occ. E (16) & 0.55 & 0.59 & 0.44 & $0.63 *$ & 0.06 & $1.00 *$ & 0.45 & $0.62 *$ & 0.38 & $0.68 *$ \\
\hline Above Avg Occ. A (16) & 0.70 & $0.74 *$ & 0.50 & $0.82 *$ & 0.64 & $0.79 *$ & 0.18 & $0.98 *$ & 0.49 & $0.86^{*}$ \\
\hline Above Avg Occ. N (16) & 0.60 & 0.64 & 0.40 & $0.72 *$ & 0.46 & $0.75^{*}$ & 0.32 & $0.76^{*}$ & 0.03 & $0.98 *$ \\
\hline Max. Observations & 1,800 & 1,134 & 944 & 1,990 & 1,346 & 1,588 & 958 & 1,976 & 1,111 & 1,823 \\
\hline
\end{tabular}

Note: Average levels of variables (rows) by below or above average wages or personality (columns) for the working sample of 2,934 working men with valid data on age 34 gross hourly wages, age-10 cognitive ability, and age-16 personality (conscientiousness, extraversion, agreeableness, and emotional stability). * indicates that the above average mean is significantly different from the below average mean, at the 5 per cent level. Number of observations shows maximum sample size of below and above average groups. 


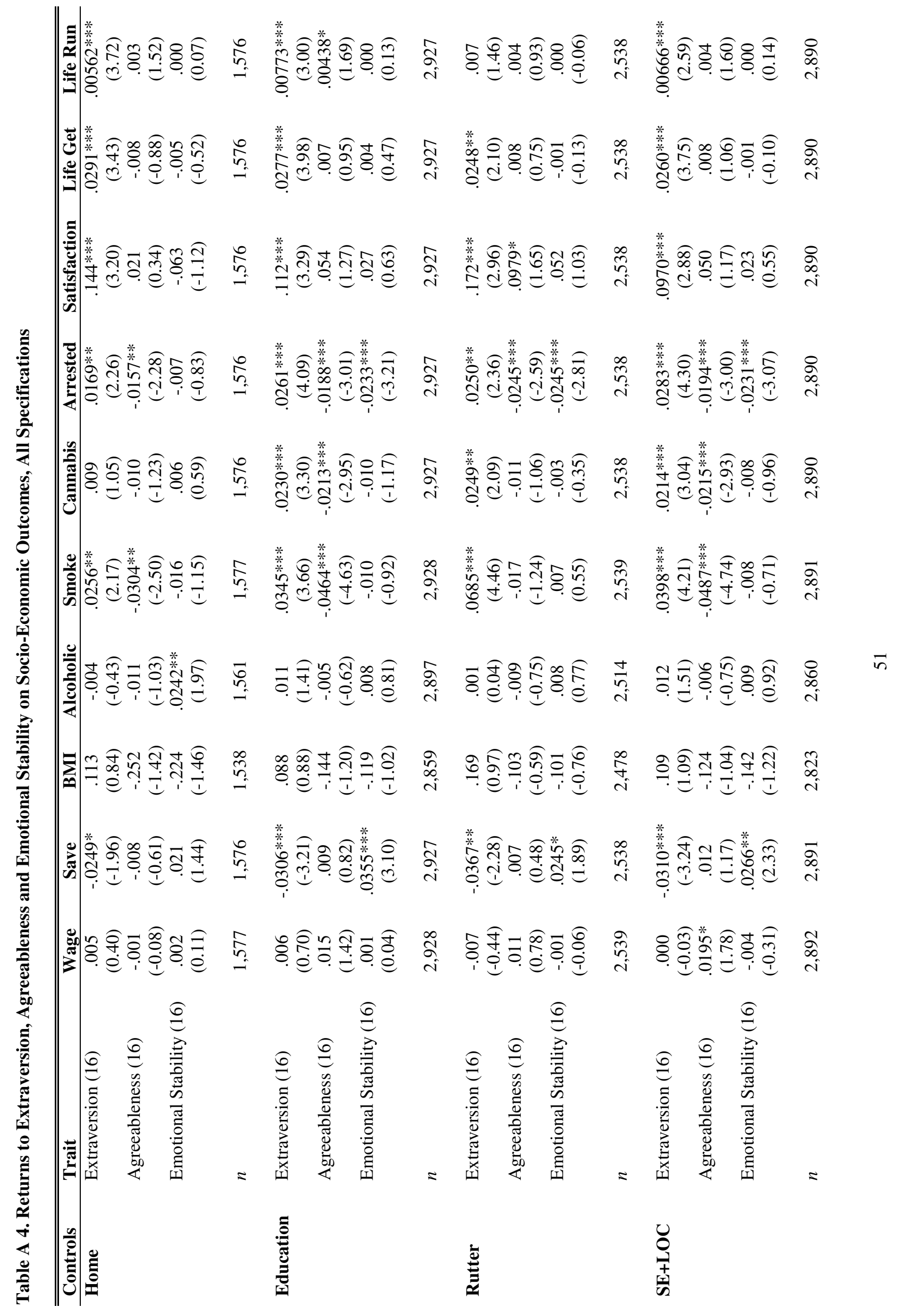




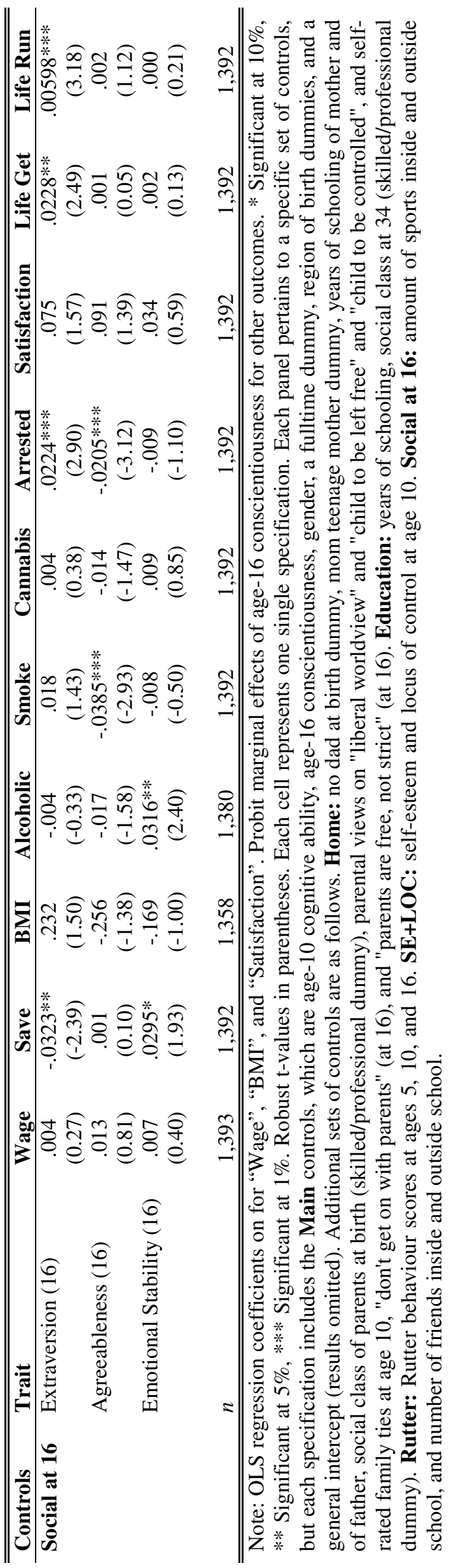


Table A 5. Mean Personality Traits by 2-digit SOC2000

\begin{tabular}{|c|c|c|c|c|c|c|c|}
\hline Description & SOC2000 & $n$ & $\begin{array}{c}\text { Share } \\
\text { of men }\end{array}$ & $\mathbf{C}$ & $\mathbf{E}$ & $\mathbf{A}$ & $\mathbf{N}$ \\
\hline Corporate Managers & 11 & 457 & $\begin{array}{c}.62 \\
(.02)\end{array}$ & $\begin{array}{c}.11 * * * \\
(.04)\end{array}$ & $\begin{array}{c}.07 \\
(.05)\end{array}$ & $\begin{array}{c}.05 \\
(.04)\end{array}$ & $\begin{array}{c}.04 \\
(.05)\end{array}$ \\
\hline $\begin{array}{l}\text { Managers and Proprietors in } \\
\text { Agriculture and Services }\end{array}$ & 12 & 67 & $\begin{array}{l}.63 \\
(.06)\end{array}$ & $\begin{array}{l}-.02 \\
(.10)\end{array}$ & $\begin{array}{l}.00 \\
(.11)\end{array}$ & $\begin{array}{l}.06 \\
(.10)\end{array}$ & $\begin{array}{l}.11 \\
(.08)\end{array}$ \\
\hline $\begin{array}{l}\text { Science and Technology } \\
\text { Professionals }\end{array}$ & 21 & 143 & $\begin{array}{c}.82 \\
(.03)\end{array}$ & $\begin{array}{c}.26 * * * \\
(.06)\end{array}$ & $\begin{array}{l}.08 \\
(.07)\end{array}$ & $\begin{array}{c}.20 * * * \\
(.06)\end{array}$ & $\begin{array}{c}.21 * * * \\
(.06)\end{array}$ \\
\hline Health Professionals & 22 & 27 & $\begin{array}{l}.59 \\
(.10)\end{array}$ & $\begin{array}{c}.41 * * * \\
(.13)\end{array}$ & $\begin{array}{l}-.01 \\
(.17)\end{array}$ & $\begin{array}{l}.36 * * * \\
(.06)\end{array}$ & $\begin{array}{l}.40 * * * \\
(.13)\end{array}$ \\
\hline $\begin{array}{l}\text { Teaching and Research } \\
\text { Professionals }\end{array}$ & 23 & 147 & $\begin{array}{l}.31 \\
(.04)\end{array}$ & $\begin{array}{c}.22 * * * \\
(.07)\end{array}$ & $\begin{array}{l}-.07 \\
(.08)\end{array}$ & $\begin{array}{c}.25 * * * \\
(.07)\end{array}$ & $\begin{array}{c}.09 \\
(.08)\end{array}$ \\
\hline $\begin{array}{l}\text { Business and Public Service } \\
\text { Professionals }\end{array}$ & 24 & 141 & $\begin{array}{l}.46 \\
(.04)\end{array}$ & $\begin{array}{c}.46^{* * * *} \\
(.05)\end{array}$ & $\begin{array}{l}-.04 \\
(.09)\end{array}$ & $\begin{array}{c}.27 * * * \\
(.05)\end{array}$ & $\begin{array}{l}.17 * * \\
(.08)\end{array}$ \\
\hline $\begin{array}{l}\text { Science and Technology } \\
\text { Associate Professionals }\end{array}$ & 31 & 94 & $\begin{array}{l}.79 \\
(.04)\end{array}$ & $\begin{array}{l}.07 \\
(.08)\end{array}$ & $\begin{array}{l}-.19 * \\
(.11)\end{array}$ & $\begin{array}{l}.15^{* *} \\
(.07)\end{array}$ & $\begin{array}{l}.12 \\
(.09)\end{array}$ \\
\hline $\begin{array}{l}\text { Health and Social Welfare } \\
\text { Associate Professionals }\end{array}$ & 32 & 139 & $\begin{array}{l}.16 \\
(.03)\end{array}$ & $\begin{array}{l}.11 \\
(.08)\end{array}$ & $\begin{array}{l}.12 \\
(.08)\end{array}$ & $\begin{array}{c}.07 \\
(.09)\end{array}$ & $\begin{array}{l}-.03 \\
(.08)\end{array}$ \\
\hline Protective Service Occupations & 33 & 71 & $\begin{array}{l}.76 \\
(.05)\end{array}$ & $\begin{array}{l}-.11 \\
(.12)\end{array}$ & $\begin{array}{c}.29 * * * \\
(.10)\end{array}$ & $\begin{array}{l}-.14 \\
(.12)\end{array}$ & $\begin{array}{l}.03 \\
(.12)\end{array}$ \\
\hline $\begin{array}{l}\text { Culture, Media and Sports } \\
\text { Occupations }\end{array}$ & 34 & 45 & $\begin{array}{l}.38 \\
(.07)\end{array}$ & $\begin{array}{l}.27 * * \\
(.11)\end{array}$ & $\begin{array}{l}-.07 \\
(.15)\end{array}$ & $\begin{array}{l}.11 \\
(.13)\end{array}$ & $\begin{array}{l}.27 * * * \\
(.10)\end{array}$ \\
\hline $\begin{array}{l}\text { Business and Public Service } \\
\text { Associate Professionals }\end{array}$ & 35 & 208 & $\begin{array}{l}.45 \\
(.03)\end{array}$ & $\begin{array}{c}.16^{* * * *} \\
(.06)\end{array}$ & $\begin{array}{l}.01 \\
(.07)\end{array}$ & $\begin{array}{l}.10^{*} \\
(.05)\end{array}$ & $\begin{array}{l}.05 \\
(.07)\end{array}$ \\
\hline Administrative Occupations & 41 & 325 & $\begin{array}{l}.23 \\
(.02)\end{array}$ & $\begin{array}{l}-.02 \\
(.06)\end{array}$ & $\begin{array}{l}-.09 \\
(.05)\end{array}$ & $\begin{array}{l}-.01 \\
(.06)\end{array}$ & $\begin{array}{l}-.07 \\
(.06)\end{array}$ \\
\hline $\begin{array}{l}\text { Secretarial and Related } \\
\text { Occupations }\end{array}$ & 42 & 79 & $\begin{array}{l}.06 \\
(.03)\end{array}$ & $\begin{array}{l}-.01 \\
(.10)\end{array}$ & $\begin{array}{l}-.06 \\
(.10)\end{array}$ & $\begin{array}{l}-.02 \\
(.11)\end{array}$ & $\begin{array}{l}-.23^{*} \\
(.13)\end{array}$ \\
\hline Skilled Agricultural Trades & 51 & 17 & $\begin{array}{c}.94 \\
(.06)\end{array}$ & $\begin{array}{l}-.49 \\
(.31)\end{array}$ & $\begin{array}{l}.28 \\
(.17)\end{array}$ & $\begin{array}{c}.01 \\
(.20)\end{array}$ & $\begin{array}{l}.37 * * * \\
(.13)\end{array}$ \\
\hline $\begin{array}{l}\text { Skilled Metal and Electrical } \\
\text { Trades }\end{array}$ & 52 & 138 & $\begin{array}{l}.98 \\
(.01)\end{array}$ & $\begin{array}{l}-.11 \\
(.09)\end{array}$ & $\begin{array}{l}-.03 \\
(.09)\end{array}$ & $\begin{array}{l}-.15 \\
(.10)\end{array}$ & $\begin{array}{c}.00 \\
(.08)\end{array}$ \\
\hline $\begin{array}{l}\text { Skilled Construction and } \\
\text { Building Trades }\end{array}$ & 53 & 66 & $\begin{array}{l}1.00 \\
(.00)\end{array}$ & $\begin{array}{l}-.20 \\
(.12)\end{array}$ & $\begin{array}{l}.14 \\
(.12)\end{array}$ & $\begin{array}{l}-.15 \\
(.17)\end{array}$ & $\begin{array}{l}.12 \\
(.10)\end{array}$ \\
\hline $\begin{array}{l}\text { Textiles, Printing and Other } \\
\text { Skilled Trades }\end{array}$ & 54 & 49 & $\begin{array}{l}.65 \\
(.07)\end{array}$ & $\begin{array}{c}-.61 * * * \\
(.20)\end{array}$ & $\begin{array}{l}-.22 \\
(.17)\end{array}$ & $\begin{array}{l}-.20 \\
(.16)\end{array}$ & $\begin{array}{l}-.17 \\
(.16)\end{array}$ \\
\hline $\begin{array}{l}\text { Caring Personal Service } \\
\text { Occupations }\end{array}$ & 61 & 138 & $\begin{array}{l}.06 \\
(.02)\end{array}$ & $\begin{array}{l}-.07 \\
(.10)\end{array}$ & $\begin{array}{l}-.02 \\
(.09)\end{array}$ & $\begin{array}{c}.04 \\
(.07)\end{array}$ & $\begin{array}{l}-.07 \\
(.09)\end{array}$ \\
\hline $\begin{array}{l}\text { Leisure and Other Personal } \\
\text { Service Occupations }\end{array}$ & 62 & 35 & $\begin{array}{l}.23 \\
(.07)\end{array}$ & $\begin{array}{l}.20^{*} \\
(.11)\end{array}$ & $\begin{array}{l}.07 \\
(.14)\end{array}$ & $\begin{array}{l}.30 * * * \\
(.05)\end{array}$ & $\begin{array}{l}-.04 \\
(.15)\end{array}$ \\
\hline Sales Occupations & 71 & 106 & $\begin{array}{l}.22 \\
(.04)\end{array}$ & $\begin{array}{l}-.23 * \\
(.12)\end{array}$ & $\begin{array}{l}-.13 \\
(.11)\end{array}$ & $\begin{array}{l}-.17 \\
(.13)\end{array}$ & $\begin{array}{l}-.21 * \\
(.12)\end{array}$ \\
\hline Customer Service Occupations & 72 & 36 & $\begin{array}{c}.08 \\
(.05)\end{array}$ & $\begin{array}{c}.02 \\
(.18)\end{array}$ & $\begin{array}{l}.03 \\
(.15)\end{array}$ & $\begin{array}{l}-.09 \\
(.15)\end{array}$ & $\begin{array}{l}-.34 * * \\
(.17)\end{array}$ \\
\hline $\begin{array}{l}\text { Process, Plant and Machine } \\
\text { Operatives }\end{array}$ & 81 & 117 & $\begin{array}{l}.76 \\
(.04)\end{array}$ & $\begin{array}{c}-.38 * * * \\
(.11)\end{array}$ & $\begin{array}{l}-.09 \\
(.10)\end{array}$ & $\begin{array}{l}-.18 * \\
(.11)\end{array}$ & $\begin{array}{l}-.03 \\
(.11)\end{array}$ \\
\hline $\begin{array}{l}\text { Transport and Mobile Machine } \\
\text { Drivers and Operatives }\end{array}$ & 82 & 80 & $\begin{array}{l}.89 \\
(.04)\end{array}$ & $\begin{array}{l}-.52 * * * \\
(.13)\end{array}$ & $\begin{array}{l}.12 \\
(.09)\end{array}$ & $\begin{array}{c}-.64 * * * \\
\quad(.17)\end{array}$ & $\begin{array}{l}-.27 * * \\
(.12)\end{array}$ \\
\hline $\begin{array}{l}\text { Elementary Trades, Plant and } \\
\text { Storage Related Occupations }\end{array}$ & 91 & 73 & $\begin{array}{l}.85 \\
(.04)\end{array}$ & $\begin{array}{l}-.22 * \\
(.13)\end{array}$ & $\begin{array}{l}.11 \\
(.13)\end{array}$ & $\begin{array}{l}-.25 \\
(.15)\end{array}$ & $\begin{array}{l}.14 \\
(.10)\end{array}$ \\
\hline $\begin{array}{l}\text { Elementary Administration and } \\
\text { Service Occupations }\end{array}$ & 92 & 131 & $\begin{array}{l}.44 \\
(.04)\end{array}$ & $\begin{array}{c}-.39 * * * \\
\quad(.11)\end{array}$ & $\begin{array}{l}-.01 \\
(.09)\end{array}$ & $\begin{array}{c}-.32 * * * \\
(.11)\end{array}$ & $\begin{array}{c}-.33 * * * \\
(.11)\end{array}$ \\
\hline$n$ & & 2,929 & 2,929 & 2,929 & 2,929 & 2,929 & 2,929 \\
\hline
\end{tabular}

Entries are mean age-16 personality traits by 2-digit 2000 Standard Occupational Classification (SOC2000). Stars indicate the mean is significantly different from the average of zero: * Significant at $10 \%$, ** Significant at $5 \%, * * *$ Significant at $1 \%$. Standard errors in parentheses. The sample applied is our working sample of 2,934 individuals with valid information on adult wages, age-10 cognitive ability, and age- 16 personality. 


\section{A3 First-stage results for $2 S L S$ reported in Section 4}

As reported in Section 4, the OLS regressions presented in Table 3 could be biased because of correlation between the independent variables and the error term. Below, in Table A5, we show the first-stage results of the 2SLS results reported in Table 6. Both when the respondent was 10 years of age and 16 years of age, their mothers reported on the same set of personality items used to construct our personality traits. We use the resulting age-10 personality constructs as instruments for those measured at age 16 (See Table 1 for reliability coefficients). We assume that measurement error in the mother-rated items at both points in time is uncorrelated, which seems plausible given the six-year window between the two surveys.

The first-stage results are strong, and the F-tests for each of the constructs well exceed the threshold of 10, ranging from 94 for age-16 agreeableness to 119 for age- 16 emotional stability $(\mathrm{N}(16))$. The second-stage estimates for all socio-economic outcomes are shown in the first panel of Table 6 in Section 4. While the first-stage results here pertain to the regression sample for age-34 wages, the first-stage results for the other socio-economic outcomes are almost identical, and are therefore not reported.

Table A 6. First-stage results for 2 SLS results in Section 4, Table 6

\begin{tabular}{|c|c|c|c|c|}
\hline & $\mathrm{C}(16)$ & $\mathrm{E}(16)$ & A(16) & $\mathrm{N}(16)$ \\
\hline Conscientiousness (10) & $\begin{array}{l}.336^{* * * *} \\
(16.27)\end{array}$ & $\begin{array}{l}-.013 \\
(-0.61)\end{array}$ & $\begin{array}{c}.033 \\
(1.55)\end{array}$ & $\begin{array}{c}.003 \\
(0.16)\end{array}$ \\
\hline Extraversion (10) & $\begin{array}{c}-.0444 * * \\
(-2.29)\end{array}$ & $\begin{array}{l}.324 * * * \\
(16.18)\end{array}$ & $\begin{array}{c}-.104 * * * \\
(-5.23)\end{array}$ & $\begin{array}{c}-.003 \\
(-0.13)\end{array}$ \\
\hline Agreeableness (10) & $\begin{array}{c}.0544 * * \\
(2.50)\end{array}$ & $\begin{array}{c}-.0467 * * \\
(-2.07)\end{array}$ & $\begin{array}{l}.277^{* * *} \\
(12.35)\end{array}$ & $\begin{array}{c}.0480 * * \\
(2.17)\end{array}$ \\
\hline Emotional Stability (10) & $\begin{array}{c}.0699 * * * \\
(3.09)\end{array}$ & $\begin{array}{c}.103^{* * * *} \\
(4.41)\end{array}$ & $\begin{array}{c}.122 * * * * \\
(5.24)\end{array}$ & $\begin{array}{l}.353 * * * \\
(15.42)\end{array}$ \\
\hline Age 10 ability & $\begin{array}{c}.112 * * * \\
(6.24)\end{array}$ & $\begin{array}{c}.021 \\
(1.13)\end{array}$ & $\begin{array}{c}.0840 * * * \\
(4.54)\end{array}$ & $\begin{array}{c}.0538 * * * \\
(2.95)\end{array}$ \\
\hline Male dummy & $\begin{array}{l}-.005 \\
(-0.13)\end{array}$ & $\begin{array}{c}.054 \\
(1.33)\end{array}$ & $\begin{array}{c}-.005 \\
(-0.12)\end{array}$ & $\begin{array}{c}.200 * * * \\
(5.02)\end{array}$ \\
\hline Fulltime dummy & $\begin{array}{c}.022 \\
(0.45)\end{array}$ & $\begin{array}{c}-.019 \\
(-0.37)\end{array}$ & $\begin{array}{c}-.021 \\
(-0.42)\end{array}$ & $\begin{array}{l}.0942 * \\
(1.91)\end{array}$ \\
\hline Constant & $\begin{array}{c}-.015 \\
(-0.39)\end{array}$ & $\begin{array}{c}-.013 \\
(-0.32)\end{array}$ & $\begin{array}{c}.019 \\
(0.49)\end{array}$ & $\begin{array}{c}-.176^{* * * *} \\
(-4.56)\end{array}$ \\
\hline$n$ & 2,782 & 2,782 & 2,782 & 2,782 \\
\hline F-test & 116.9 & 105.1 & 94.24 & 119.4 \\
\hline R-squared & .190 & .134 & .141 & .168 \\
\hline
\end{tabular}

Note: First-stage regression results for 2SLS estimates reported for age-34 wage in Table 6. * Significant at $10 \%, * *$ Significant at 5\%,*** Significant at 1\%. T-values in parentheses. All specifications control for age-10 cognitive ability, gender, a fulltime dummy, region of birth dummies (results omitted), and a general intercept (Constant). 